NASA/TM-1998-206540

$$
\begin{aligned}
& N-06 \\
& 1998 \\
& 048743
\end{aligned}
$$

NASA

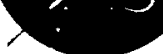

\title{
Design and Calibration of the X-33 Flush Airdata Sensing (FADS) System
}

Stephen A. Whitmore, Brent R. Cobleigh, and Edward A. Haering

Dryden Flight Research Center

Edwards, Califormia 


\section{The NASA STI Program Office ... in Profile}

Since its founding, NASA has been dedicated to the advancement of aeronautics and space science. The NASA Scientific and Technical Information (STI) Program Office plays a key part in helping NASA maintain this important role.

The NASA STI Program Office is operated by Langley Research Center, the lead center for NASA's scientific and technical information. The NASA STI Program Office provides access to the NASA STI Database, the largest collection of aeronautical and space science STI in the world. The Program Office is also NASA's institutional mechanism for disseminating the results of its research and development activities. These results are published by NASA in the NASA STI Report Series, which includes the following report types:

- TECHNICAL PUBLICATION. Reports of completed research or a major significant phase of research that present the results of NASA programs and include extensive data or theoretical analysis. Includes compilations of significant scientific and technical data and information deemed to be of continuing reference value. NASA's counterpart of peer-reviewed formal professional papers but has less stringent limitations on manuscript length and extent of graphic presentations.

- TECHNICAL MEMORANDUM. Scientific and technical findings that are preliminary or of specialized interest, e.g., quick release reports, working papers, and bibliographies that contain minimal annotation. Does not contain extensive analysis.

- CONTRACTOR REPORT. Scientific and technical findings by NASA-sponsored contractors and grantees.
- CONFERENCE PUBLICATION. Collected papers from scientific and technical conferences, symposia, seminars, or other meetings sponsored or cosponsored by NASA.

- SPECIAL PUBLICATION. Scientific, technical, or historical information from NASA programs, projects, and mission, often concerned with subjects having substantial public interest.

- TECHNICAL TRANSLATION. Englishlanguage translations of foreign scientific and technical material pertinent to NASA's mission.

Specialized services that complement the STI Program Office's diverse offerings include creating custom thesauri, building customized databases, organizing and publishing research results . . . even providing videos

For more information about the NASA STI Program Office, see the following:

- Access the NASA STI Program Home Page at http://w'w'sti.nasa.gov

- E-mail your question via the Internet to help@sti.nasa.gor

- Fax your question to the NASA Access Help Desk at (301) 621-0134

- Telephone the NASA Access Help Desk at (301) 621-0390

- Write to: NASA Access Help Desk NASA Center for AeroSpace Information 800 Elkridge Landing Road Linthicum Heights, MD 21090-2934 
NASA/TM-1998-206540

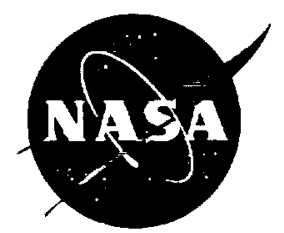

\section{Design and Calibration of the X-33 Flush Airdata Sensing (FADS) System}

Stephen A. Whitmore, Brent R. Cobleigh, and Edward A. Haering

Dryden Flight Research Center

Edwards, California

National Aeronautics and

Space Administration

Dryden Flight Research Center

Edwards, California 93523-0273

January 1998 


\section{NOTICE}

Use of trade names or names of manufacturers in this document does not constitute an official endorsement of such products or manufacturers, either expressed or implied, by the National Aeronautics and Space Administration.

Available from:

NASA Center for AeroSpace Information

800 Elkridge Landing Road

Linthicum Heights, MD 21090-2934

Price Code: A 16
National Technical Information Service 5285 Port Royal Road Springfield, VA 22161

Price Code: A16 


\title{
DESIGN AND CALIBRATION OF THE X-33 FLUSH AIRDATA SENSING (FADS) SYSTEM
}

\author{
Stephen A. Whitmore, ${ }^{*}$ Brent R. Cobleigh, ${ }^{\dagger}$ and \\ Edward A. Haering, Jr. \\ NASA Dryden Flight Research Center \\ Edwards, California
}

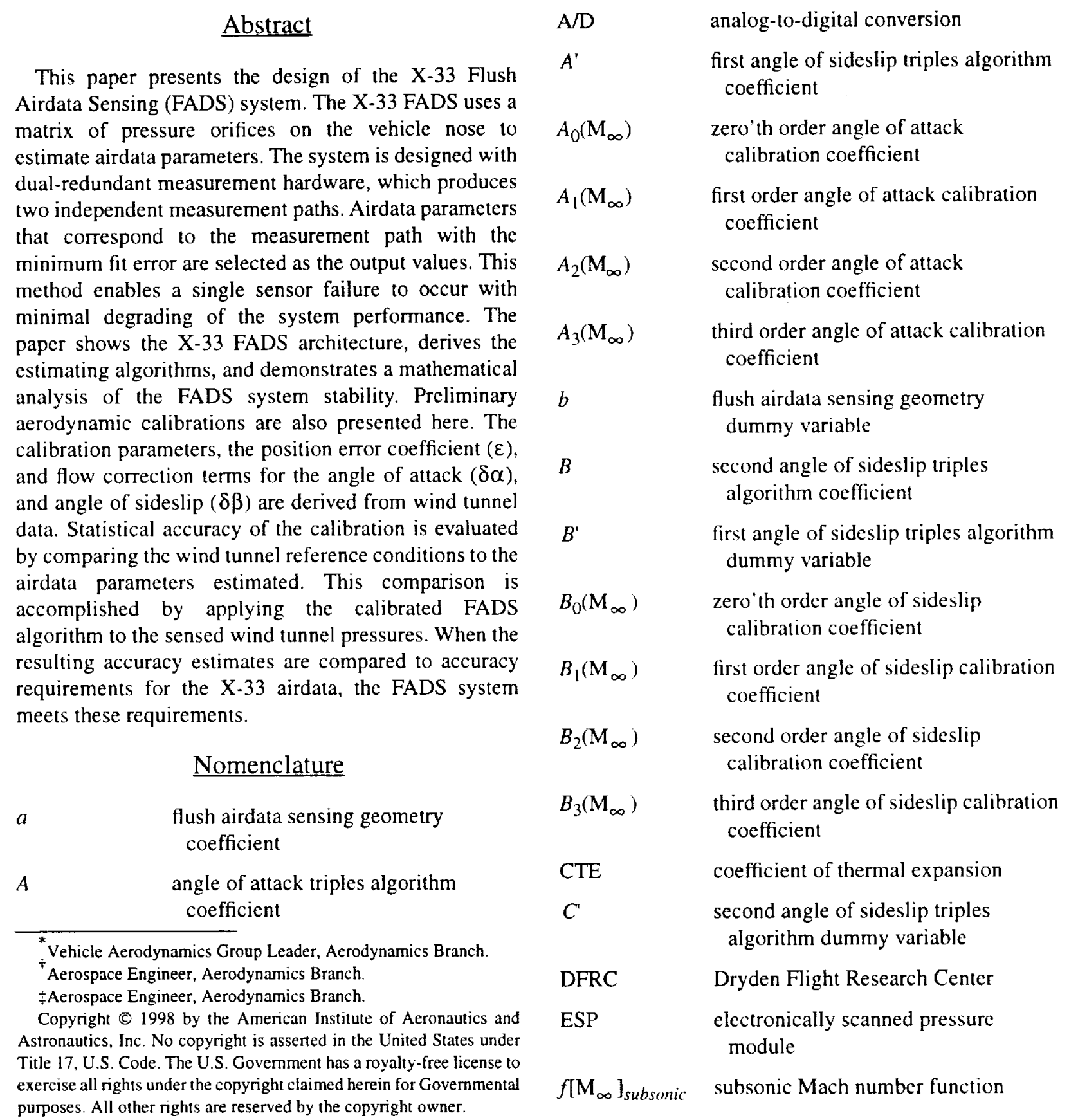




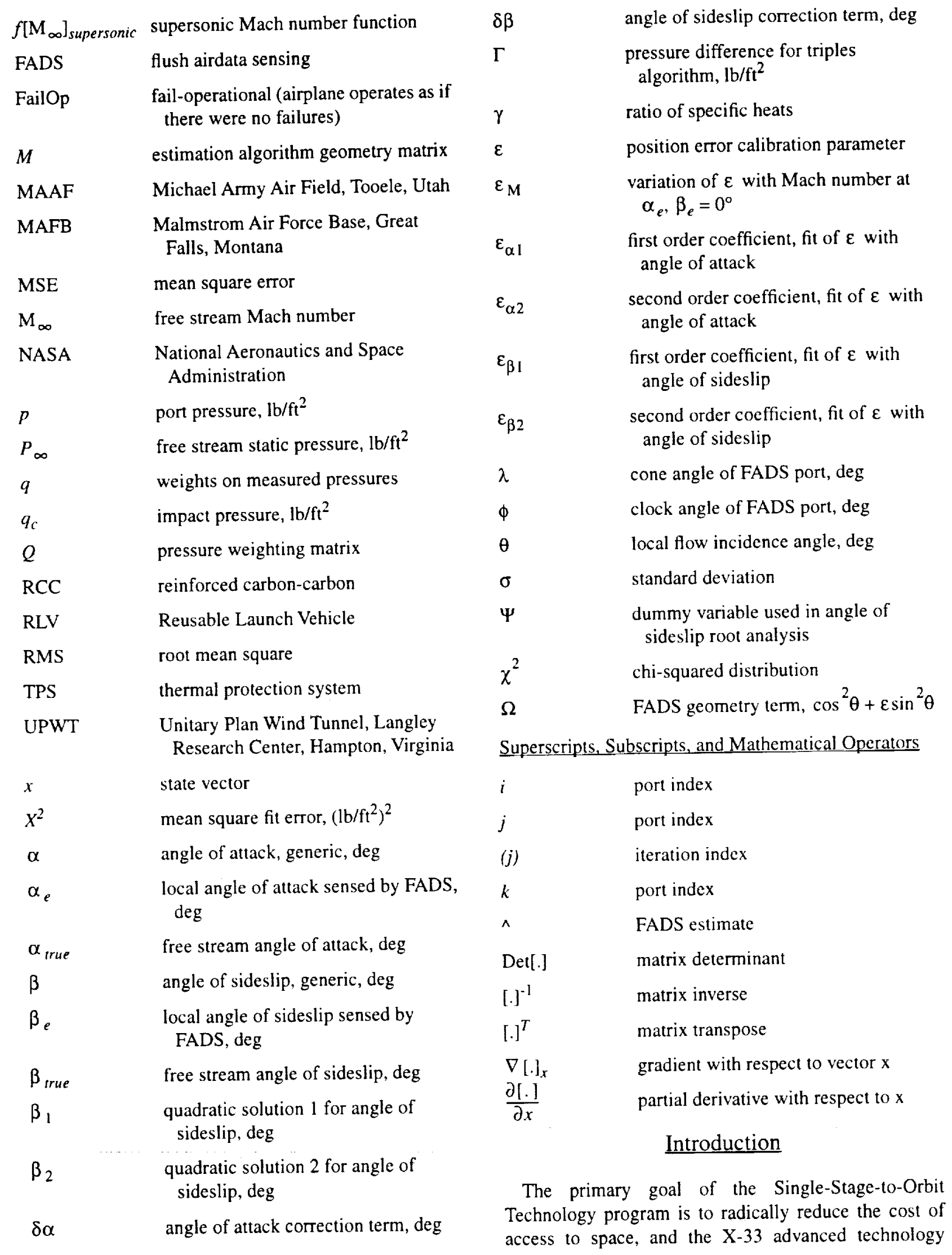


demonstrator is the centerpiece of this effort. The X-33 design is a 53-percent scale model of the Lockheed Martin VentureStar ${ }^{\mathrm{TM}}{ }^{*}$ Reusable Launch Vehicle (RLV) and is based on a lifting-body design which features two linear aerospike rocket engines. The autonomous-flight X-33 will launch from Edwards Air Force Base at Edwards, California and land at one of two sites: Michael Army Air Field (MAAF) in Tooele, Utah, or Malmstrom Air Force Base (MAFB) in Great Falls, Montana. The vehicle is designed to achieve a peak altitude near $300,000 \mathrm{ft}$ and speeds of greater than Mach 12. After atmospheric re-entry, the X-33 returns to Earth with an unpowered horizontal landing. A comparison of the $\mathrm{X}-33$ and VentureStar ${ }^{\mathrm{TM}}$ vehicles is presented in figure 1.

Because the $\mathrm{X}-33$ is to perform an unpowered landing, knowledge of the dynamic pressure, angle of attack, and surface winds is critical, so that the terminal area energy management (TAEM) can ensure that the target runway be reached under a wide variety of atmospheric conditions. Direct feedback of angle of attack and angle of sideslip are also required for gust load alleviation on the vehicle airframe during the ascent of the flight. Thus, it was determined early in the X-33 program that the full airdata state, including Mach number, angle of attack, angle of sideslip, dynamic pressure, airspeed and altitude, would be a flight-critical requirement for both the RLV and the X-33.

To achieve the TAEM and ascent airdata requirements the airdata system must be operational between Mach 0.20 and Mach 4.0 and meet the following 1- $\sigma$ accuracy requirements.

1. Mach Number: \pm 5.0 percent accuracy for $2.5 \leq \mathrm{M}_{\infty} \leq 4.0, \pm 2.50$ percent accuracy for $0.6 \leq \mathrm{M}_{\infty}<2.5, \pm 0.015$ absolute error between $\mathrm{M}_{\infty}=0.20$ and $\mathrm{M}_{\infty}=0.60$,

2. Angle of attack: $\pm 1.5^{\circ}$ absolute accuracy for first three flights, $\pm 0.50^{\circ}$ thereafter,

3. Angle of sideslip: $\pm 0.5^{\circ}$ absolute accuracy for all flights.

4. Geopotential altitude: $\pm 200 \mathrm{ft}$ absolute accuracy for $0.2 \leq \mathrm{M}_{\infty} \leq 4.0$.

5. Dynamic Pressure: $\pm 15 \mathrm{lb} / \mathrm{ft}^{2}$ for $0.2 \leq \mathrm{M}_{\infty} \leq 4.0$.

To determine the best means of meeting the airdata requirements, NASA Dryden Flight Research Center (DFRC) performed a feasibility study to compare the

\footnotetext{
"Lockheed Martin, Inc., Mountain View, California
}

performance and cost of a Flush Airdata Sensing (FADS) system to a set of deployable probes similar to that system installed on the space shuttle. This study concluded that a FADS system was more economical by a factor of approximately two. Two issues made the probe-based system prohibitively expensive: 1) integration onto the X-33 airframe, and 2) system calibration. The FADS system requires no deployment mechanisms and can be integrated directly onto the vehicle nosecap with no movable parts. Because the FADS system does not probe the flowfield, but instead uses the natural contours of the forebody, the flow field is much cleaner and is easier to calibrate. An additional advantage of the FADS system is that it offers the potential to sense airdata on ascent, an option not available to the probe-based system. Based on the results of this study, Lockheed Martin Skunkworks, Palmdale, California, selected the FADS system in favor of the deployable probes.

The DFRC FADS design builds on work which originated in the early 1960's with the X-15 program, ${ }^{1}$ continued at NASA Langley,, 3 and Dryden Flight Research Centers ${ }^{4,5}$ in the 1970's and 1980's, and recently concluded flight testing of an onboard real-time system in the early 1990's. 6,7 The FADS concept, in which airdata are inferred from nonintrusive surface pressure measurements, does not require probing of the local flow field to compute airdata parameters. This innovation allows the extreme hypersonic heating caused by the small radius of a flow-sensing probe to be avoided, which extends the useful range of the airdata measurement system to the hypersonic flow regime. This paper describes the X-33 FADS system design, develops the aerodynamic model which relates the airdata parameters to the measured pressures, and derives the computational algorithms used to compute the airdata from the pressure measurements. Wind tunnel calibration and validation of the FADS system is also presented.

\section{Flush Airdata Sensing Aerodynamic Model}

The fundamental concept of the FADS system is that airdata parameters can be estimated from flush surface pressure measurements. To perform this estimation, the airdata states must be related to the surface pressures by an aerodynamic model that captures the salient features of the flow, and is valid over a large Mach number range. To be useful, the model must be simple enough to be inverted in real-time so that the airdata parameters can be extracted. To solve the problem of describing a complex flow scenario with a simple model, the FADS 
aerodynamic model was derived as a splice of the closedform potential flow solution for a blunt body, ${ }^{8}$ applicable at low subsonic speeds; and the modified Newtonian flow model, ${ }^{9}$ applicable at hypersonic speeds. Both potential flow and modified Newtonian flow describe the measured pressure coefficient in terms of the local surface incidence angle. To blend the two solutions over a large range of Mach numbers, a calibration parameter $(\varepsilon)$ was allowed for. This parameter must be empirically calibrated to allow for the effects of flow compression, body shape, and other systematic effects such as shock wave compression or Prandtl-Meyer expansion on the forebody. The resulting model is ${ }^{6}$

$$
p_{i}=q_{c}\left[\cos ^{2}\left(\theta_{i}\right)+\varepsilon \sin ^{2}\left(\theta_{i}\right)\right]+P_{\infty}
$$

In equation $1, \theta_{i}$ is the flow incidence angle between the surface normal at the $i$ 'th port and the velocity vector. The incidence angle is related to the local (or effective) angle of attack, $\left(\alpha_{e}\right)$ and angle of sideslip, $\left(\beta_{e}\right)$ by $^{6}$

$$
\begin{aligned}
\cos \left(\theta_{i}\right)= & \cos \left(\alpha_{e}\right) \cos \left(\beta_{e}\right) \cos \left(\lambda_{i}\right) \\
& +\sin \left(\beta_{e}\right) \sin \left(\phi_{i}\right) \sin \left(\lambda_{i}\right) \\
& +\sin \left(\alpha_{e}\right) \cos \left(\beta_{e}\right) \cos \left(\phi_{i}\right) \sin \left(\lambda_{i}\right)
\end{aligned}
$$

In equation 2 , the cone angle $(\lambda)$ is the total angle the normal to the surface makes with respect to the longitudinal axis of the nosecap. The clock angle $(\phi)$ is the clockwise angle looking aft around the axis of symmetry starting at the bottom of the fuselage. These coordinate angles are depicted in figure 2 . The remaining parameters in equation 1 are impact pressure $\left(q_{c}\right)$ and the free stream static pressure $\left(P_{\infty}\right)$. Using these four basic parameters $\left(\alpha_{e}, \beta_{e}, q_{c}\right.$, and $\left.P_{\infty}\right)$ most other airdata quantities of interest may be directly calculated.

In addition to the calibration for $\varepsilon$, the local flow incidence angles $\left(\alpha_{e}\right.$ and $\beta_{e}$ ) must be related by calibrations to the true free stream flow angles. These flow-angle calibrations account for such additional systematic effects as bow shock flow deflection and body-induced upwash and sidewash. For the X-33 a preliminary set of calibrations is derived using wind tunnel data. The wind tunnel tests and the results of the calibrations are discussed in detail in the Calibration of the Aerodynamic Model section.

\section{The X-33 Flush Airdata Sensing Pressure Matrix}

Since the simple model of equation 1 is derived from potential and Newtonian flow around a blunt body, it is most valid near the vehicle stagnation point. Thus, the most desirable location for the FADS pressure matrix is the reinforced carbon-carbon (RCC) nosecap which is used for the vehicle thermal protection system (TPS) and is in the stagnation region. The nosecap is hemispherical with a radius of $47.58 \mathrm{in}$. and extends longitudinally aft from the nose tip $20.8 \mathrm{in.}$ Aft of the RCC nosecap an RCC skirt is used to protect the windward side of the vehicle, and a honeycomb metallic TPS is used for the leeward sides.

\section{Measurement Locations}

The number of measurements in the $\mathrm{X}-33$ pressure matrix was selected as a compromise between the need to accurately measure the flow conditions at the nose and the cost of locating ports on the vehicle. Since there are four airdata states and a calibration parameter to be estimated, at least five independent pressure measurements must be available to derive the entire airdata state. Using five sensors to estimate the airdata is equivalent to a higher order spline fit and results in an estimating algorithm which is sensitive to noise in the measured pressures. Providing an additional sixth sensing location mitigates the noise sensitivity, increases redundancy options, and results in a system which gives overall superior performance.

Figure 3 shows the FADS measurement locations. Five measurement locations are on the nosecap, and a sixth measurement location is on the carbon-carbon skirt. The layout along meridian lines allows the calculations for angle of attack to be decoupled from the calculations for angle of sideslip using the triples algorithm, the real-time airdata algorithm for the X-33. The mathematical properties of the triples algorithm will be discussed in detail in the Flush Airdata Sensing Estimation Algorithm section, and the algorithm equations are derived in the appendix. The system layout is designed to give good sensitivity for local angles of attack varying from $-20^{\circ}$ to $45^{\circ}$, and angles of sideslip of up to $\pm 20^{\circ}$. The nominal clock and cone angles of the X-33 FADS ports are tabulated in Table 1.

Table 1. X-33 FADS ports, clock and cone angles.

\begin{tabular}{ccc}
\hline \hline Port no. & $\phi_{i}$, deg & $\lambda_{i}$, deg \\
\hline 1 & 180 & 20 \\
2 & 270 & 20 \\
3 & 0 & 0 \\
4 & 90 & 20 \\
5 & 0 & 20 \\
6 & 0 & 45 \\
\hline
\end{tabular}




\section{Pneumatic Layout}

Each X-33 flight-critical measurement subsystem must have a fail-operational (FailOp) capability. That is, the subsystem can tolerate one failure anywhere in the system software or hardware and still produce a usable result. The FADS design exploits the built-in redundancy of the pressure port matrix to achieve FailOp capability with dual redundant system hardware. This dual redundancy is achieved at each surface measurement location by installing a plug with two surface ports.

Figure 4 shows an exploded view of the plug design. To survive the peak stagnation temperature of approximately $2000^{\circ} \mathrm{F}$, the FADS plugs are fabricated from $\mathrm{C}-103$ niobium alloy. ${ }^{10}$ The $\mathrm{C}-103$ alloy has a melting point in excess of $4000^{\circ} \mathrm{F}$ and a maximum working temperature of approximately $2500^{\circ} \mathrm{F}$. An additional advantage of using niobium alloy for the surface plug is that the alloy has a coefficient of thermal expansion (CTE) which is very close to the CTE of carbon-carbon. ${ }^{11}$ This match of the thermal expansion properties ensures that hot gas leakage around the plug is unlikely to occur. The relatively close match of the two materials expansion coefficients also ensures that undue thermal stresses are not imparted to the RCC nosecap when high heating loads are applied. The plug design was derived from an adaptation of the Space Shuttle Entry Airdata System ${ }^{3}$ which used niobium inserts with excellent success.

On each plug the two surface ports are connected to the pneumatic tubing using a high-temperature titanium alloy braze. The individual surface ports are plumbed to the measurement sensors using approximately $8-12 \mathrm{ft}$ of pneumatic tubing with an approximate inside diameter of $0.21 \mathrm{in}$. The pneumatic response of this arrangement was analyzed extensively along the X-33 flight trajectory. Based on these analyses, it was determined that the pneumatic latencies in the system would not introduce significant errors into the airdata estimates.

\section{Computational Architecture and Redundancy Management}

A schematic of the computational architecture and redundancy management scheme for the X-33 FADS is presented in figure 5 . The design of the X-33 FADS system provides a total of twelve surface pressure measurements; however, the pressures from the dual redundant pressure ports are always analyzed independently. Defining data flow path $I$ as the set of computations which use the grouping of the six upper and outboard pressure measurements on each plug, and data flow path $I I$ as the set of computations which uses the six lower and inboard pressures, then the FailOp capability of the system will always be ensured by selecting the computational path with the minimum mean square fit error. The mean square fit error is computed as

$$
\begin{gathered}
\sum_{i=1}^{6} q_{i}\left[P_{i}^{(\text {measured })}-\left(\hat { q } _ { c } \left[\cos ^{2} \theta_{i}\left(\hat{\alpha}_{e}, \hat{\beta}_{e}\right)\right.\right.\right. \\
X^{2}=\frac{\left.\left.+\varepsilon \sin ^{2} \theta_{i}\left(\hat{\alpha}_{e}, \hat{\beta}_{e}\right)\right]+\hat{P}_{\infty}\right]^{2}}{\sum_{i=1}^{6} q_{i}}
\end{gathered}
$$

where, the ${ }^{\wedge}$ designates a quantity estimated by the FADS algorithm. This redundancy management scheme selects the system with the best overall fit consistency, and allows for a soft sensor failure (one which is not detected by the hardware diagnostics) to occur without degrading the performance of the system.

If the mean square error (MSE) of the output flow path is normalized by an expected population variance (that is, by the expected range of fit error that is allowable for a system with no failures) then the MSE becomes distributed as $\chi^{2}$ and is a good indicator of the absolute system health. This chi-squared approach was developed and successfully employed by Whitmore, et al ${ }^{12.13}$ on previous flight tests. Expected values for the fit error ranges are still to be determined from additional wind tunnel tests.

\section{The Flush Airdata Sensing Estimating Algorithm}

The aerodynamic model of equations 1 and 2 is inherently nonlinear in terms of the state parameters and can not be directly inverted. A nonlinear regression method in which the equations are recursively linearized and inverted using iterative least squares has been developed and successfully flight tested. ${ }^{14}$ Problems with the stability of the algorithm were encountered, however, and the algorithm required special software patches to maintain stability. Because the FADS is to be used for closed-loop flight control on the X-33, the nonlinear regression algorithm was determined to be too risky and was abandoned.

A new solution algorithm was developed for the $\mathrm{X}-33$ FADS. A better solution algorithm is offered by taking strategic combinations of three sensor readings that will decouple the flow angularity states from the static and 
impact pressure states and the aerodynamic calibration. Detailed derivations of the FADS estimator equations are presented in the appendix. For completeness, portions necessary to explain the flow of the algorithm are restated here.

\section{Angle of Altack Triples Estimator}

By strategically taking the differences of three surface pressures (referred to in this paper as "triples") the pressure related states $\left(q_{c}, P_{\infty}\right.$, and $\left.\varepsilon\right)$ are eliminated from equation 1 . The resulting pressure equation is

$$
\Gamma_{i k} \cos ^{2} \theta_{j}+\Gamma_{j i} \cos ^{2} \theta_{k}+\Gamma_{k j} \cos ^{2} \theta_{i}=0
$$

where

$$
\Gamma_{i k}=\left(p_{i}-p_{k}\right), \Gamma_{j i}=\left(p_{j}-p_{i}\right), \Gamma_{k j}=\left(p_{k}-p_{j}\right)
$$

and $p_{i}, p_{j}$, and $p_{k}$ are the pressures used in the data triple. In equation 4 the local angle of attack can be decoupled from the local angle of sideslip using only pressures aligned along a vertical meridian where $\phi=0^{\circ}$ or $180^{\circ}$. In this geometry arrangement, terms related to angle of sideslip fall out of equation 4 . For $|\alpha| \leq 45^{\circ}$ the solution for $\alpha$ is

$$
\alpha=\frac{1}{2} \tan ^{-1}\left[\frac{A}{B}\right]
$$

where

$$
\begin{aligned}
A= & \Gamma_{i k} \sin ^{2} \lambda_{j}+\Gamma_{j i} \sin ^{2} \lambda_{k}+\Gamma_{k j} \sin ^{2} \lambda_{i} \\
B= & \Gamma_{i k} \cos \phi_{j} \sin \lambda_{j} \cos \lambda_{j} \\
& +\Gamma_{j i} \cos \phi_{k} \sin \lambda_{k} \cos \lambda_{k} \\
& +\Gamma_{k j} \cos \phi_{i} \sin \lambda_{i} \cos \lambda_{i}
\end{aligned}
$$

When $|\alpha|>45^{\circ}$ the correct solution is given by the complement of equation $5(\mathrm{a})$

$$
\alpha=\frac{1}{2}\left(\pi-\tan ^{-1}\left[\frac{A}{B}\right]\right)
$$

For the X-33 there are four possible independent combinations of $\alpha$-triples on the vertical meridian. The clock and cone angles corresponding to these triples combinations are presented in Table 2.

Table 2. Angle of attack triples, clock and cone angles.

\begin{tabular}{ccrrrrr}
\hline \hline Triple no. & $\begin{array}{c}\phi_{i}, \\
\operatorname{deg}\end{array}$ & $\begin{array}{r}\lambda_{i}, \\
\operatorname{deg}\end{array}$ & $\begin{array}{r}\phi_{j}, \\
\operatorname{deg}\end{array}$ & $\begin{array}{c}\lambda_{j}, \\
\operatorname{deg}\end{array}$ & $\begin{array}{c}\phi_{k}, \\
\operatorname{deg}\end{array}$ & $\begin{array}{c}\lambda_{k}, \\
\operatorname{deg}\end{array}$ \\
\hline 1 & 0 & 0 & 0 & 20 & 180 & 20 \\
2 & 0 & 0 & 0 & 20 & 0 & 45 \\
3 & 0 & 0 & 180 & 20 & 0 & 45 \\
4 & 0 & 20 & 180 & 20 & 0 & 45 \\
\hline \hline
\end{tabular}

The output angle of attack estimate is determined as the mean of the values computed using the four individual triples. This averaging procedure provides a measure of noise rejection for the estimator. Clearly, if one of the ports along the vertical meridian is deemed unusable and is weighted out of the algorithm, then only one valid triple remains for computing the angle of attack.

\section{Angle of Sideslip Estimator}

Once the local angle of attack has been estimated, then the angle of sideslip may be evaluated using any combination of the available ports, other than the obvious set in which all three ports lie on the vertical meridian. The result, derived in the appendix, is a quadratic equation in $\tan \beta$.

$$
A^{\prime} \tan ^{2} \beta+2 B^{\prime} \tan \beta+C=0
$$

where

$$
\begin{aligned}
& A^{\prime}=\left\{\Gamma_{i k} b_{j}^{2}+\Gamma_{j i} b_{k}^{2}+\Gamma_{k j} b_{i}^{2}\right\} \\
& B^{\prime}=\left\{\Gamma_{i k} a_{j} b_{j}+\Gamma_{j i} a_{k} b_{k}+\Gamma_{k j} a_{i} b_{i}\right\} \\
& C=\left\{\Gamma_{i k} a_{j}^{2}+\Gamma_{j i} a_{k}^{2}+\Gamma_{k j} a_{i}^{2}\right\}
\end{aligned}
$$

and 


$$
\begin{aligned}
a_{\{i j k\}}= & \cos \alpha \cos \lambda_{\{i j k\}} \\
& +\sin \alpha \sin \lambda_{\{i j k\}} \cos \phi_{\{i j k\}} \\
b_{\{i j k\}}= & \sin \lambda_{\{i j k\}} \sin \phi_{\{i j k\}}
\end{aligned}
$$

Equation 6 has two solutions. However, unlike the solution for angle of attack these solutions cannot be reduced to a single obvious choice for the angle of sideslip roots. Determining which root is correct depends on the port arrangement used to determine the angle of sideslip. Since only four angle-of-sideslip ports are required for a redundant measurement system, the number of possible angle-of-sideslip triples to be considered is reduced to a more manageable number by removing the upper $20^{\circ}$ port (port no. 1) on the vertical meridian. When this port is eliminated the number of available triples reduces to seven. The list of triples to be considered is tabulated in Table 3.

Table 3. Angle of sideslip triples, clock and cone angles.

\begin{tabular}{ccrrrrr}
\hline $\begin{array}{c}\text { Triple } \\
\text { no. }\end{array}$ & $\begin{array}{c}\phi_{i}, \\
\text { deg }\end{array}$ & $\begin{array}{r}\lambda_{i}, \\
\operatorname{deg}\end{array}$ & $\begin{array}{r}\phi_{j}, \\
\operatorname{deg}\end{array}$ & $\begin{array}{c}\lambda_{j}, \\
\operatorname{deg}\end{array}$ & $\begin{array}{c}\phi_{k}, \\
\operatorname{deg}\end{array}$ & $\begin{array}{c}\lambda_{k}, \\
\operatorname{deg}\end{array}$ \\
\hline 1 & 0 & 0 & 90 & 20 & 270 & 20 \\
2 & 0 & 20 & 90 & 20 & 270 & 20 \\
3 & 0 & 0 & 90 & 20 & 0 & 20 \\
4 & 0 & 0 & 270 & 20 & 0 & 20 \\
5 & 0 & 45 & 90 & 20 & 270 & 20 \\
6 & 0 & 0 & 90 & 20 & 0 & 45 \\
7 & 0 & 0 & 270 & 20 & 0 & 45 \\
\hline \hline
\end{tabular}

As developed in the appendix, port arrangements 2 and 5 have mathematical singularities at $0^{\circ} \beta_{e}$ for certain values of $\alpha_{e}$. Near these singularities all three pressures in the triple have nearly the same value, and the triples equations become ill-conditioned. Away from these singularities, the solution for $\beta_{e}$ is given by the root whose absolute value is closest to zero. However, as derived in the appendix, near the singularity the solution is indeterminate, and the proper solution cannot be distinguished.

For port arrangement 2 the singularity occurs at $0^{\circ} \alpha_{e}$. For port arrangement 5 the singularity is at $18.2^{\circ} \alpha_{e}$. For the X-33 FADS design, which requires four ports for the estimator, the singularity problem is managed by a simple algorithm in which port number 6 $\{\lambda, \phi\}=\left\{0^{\circ}, 45^{\circ}\right\}$ is used only when $\alpha_{e}$ is outside of the range from $17^{\circ}$ to $20^{\circ}$. Similarly, only when $\alpha_{e}$ is between the range from $17^{\circ}$ to $20^{\circ}$, then is port number 5 $\{\lambda, \phi\}=\left\{0^{\circ}, 20^{\circ}\right\}$ used as the fourth angle-of-sideslip port.

As with the angle-of-attack algorithm, the output angle of sideslip estimate is determined as the mean of the values computed using the four individual triples. Clearly, if one of the ports along the vertical meridian is deemed unusable and is weighted out of the algorithm, then only one valid triple remains for computing the angle of sideslip.

\section{Mach Number. Static Pressure, and Impact Pressure Estimator}

Once the values of $\alpha_{e}$ and $\beta_{e}$ have been determined, then the incidence angles at all of the ports can be evaluated, and only $\varepsilon, P_{\infty}$, and $q_{c}$ remain as unknowns in the pressure equations. As derived in the appendix, $\varepsilon$ is implicitly a function of $P_{\infty}$ and $q_{C}$ and the resulting system of equations is nonlinear. The solutions for $P_{\infty}$ and $q_{c}$ must be extracted iteratively. Defining the matrices

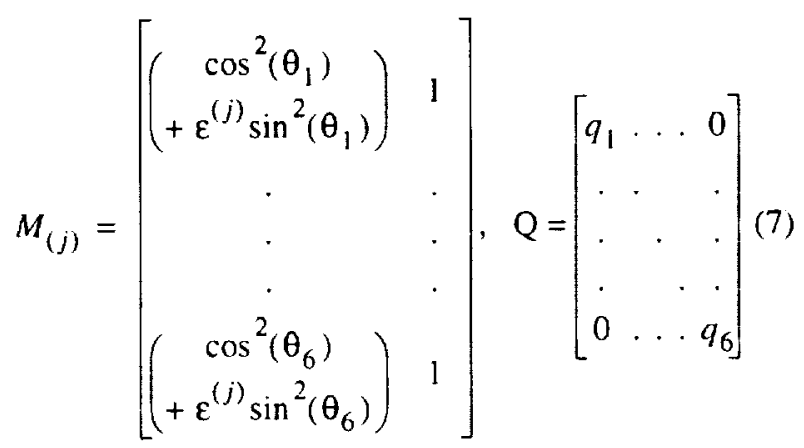

the original flow model (eq. 1) can be used to develop an iterative estimator of the form

$$
\left[\begin{array}{c}
\hat{q}_{c} \\
\hat{P}_{\infty}
\end{array}\right]_{(j+I)}=\left\{\left[M_{(j)}^{T} Q M_{(j)}\right]^{-1} M_{(j)}^{T} Q\right\}\left[\begin{array}{c}
p_{1} \\
\cdot \\
\cdot \\
\cdot \\
p_{6}
\end{array}\right]
$$

The subscript $(j)$ refers the result of the $j$ th iteration. The notation $M_{(j)}$ refers to the matrix of equation 8 , with $\varepsilon$ being evaluated, using the values for Mach number resulting from the previous iteration. The $q_{i}$ terms are weights which have a nominal value of 1.0. Setting the 
value of $q_{i}$ to zero, weights the $i$ 'th pressure reading out of the algorithm. Equation 8 is derived in detail in the appendix.

Given $q_{c}$ and $P_{\infty}$, Mach number can be computed using normal one-dimensional fluid mechanics relationships. Subsonically, Mach number can be calculated directly using isentropic flow laws, where for $\gamma=1.4$

$$
\frac{q_{c}}{P_{\infty}}=\left[1+.2 \mathrm{M}_{\infty}^{2}\right]^{3.5}-1
$$

Supersonically, the solution is computed using the Rayleigh pitot equation which is derived from adiabatic normal shock wave relationships. ${ }^{15}$ For $\gamma=1.4$

$$
\frac{q_{c}}{P_{\infty}}=\frac{166.92 \mathrm{M}_{\infty}^{7}}{\left[7 \mathrm{M}_{\infty}^{2}-1\right]^{2.5}}-1
$$

Equation 9(b) is solved using a Taylor series expansion and a reversion of series to solve for Mach number. ${ }^{16}$

For high Mach numbers, a very significant temperature rise occurs across the bow shock wave and the fluid no longer behaves as a calorically perfect gas. The large temperature rise across the shock wave causes vibrational modes of the air molecules to excite, which draws energy away from the flow. Thus the stagnation temperatures actually encountered are considerably lower than those which would be computed if perfect gas calculations with $\gamma=1.4$ were used. ${ }^{17}$

As a result of this nonadiabatic flow behavior, some error is expected to occur in the Mach number calculation using equation 9(b). Fortunately, because pressure is a mechanical quantity and depends primarily upon the mechanical aspects of the flow, influences caused by high-temperature gas properties are secondary. Numerical analyses of equation 9(b) have shown that the error introduced is less than 0.2 percent for Mach numbers below 4.0. ${ }^{15}, 18,19$ This error is acceptable for the X-33 design.

\section{Numerical Stability of the Flush Airdata Sensing Algorithm Iteration}

Since equations 8 through 9 are to be implemented as part of a real-time airdata estimation algorithm, it is essential that potential instabilities in the iteration scheme be identified. In general it is not possible to analyze the stability of nonlinear equations with two unknowns; however, a linearized stability analysis determines the behavior of the system with respect to small disturbances. For a discrete iteration, eigenvalues with magnitudes less than 1.0 indicate stability ${ }^{20}$ for the corresponding eigenmode. As the magnitudes of the eigenvalues approach unity, the system is relatively less stable, and more iterations are required for convergence. Eigenvalues with magnitudes greater than unity indicate that the iteration will diverge.

For the FADS algorithm there are two eigenvalues. As derived in the appendix, these eigenvalues are primarily a function of Mach number and, to a much lesser extent, angle of attack. The individual values of $q_{c}$ and $P_{\infty}$ did not affect the stability of the iteration, only their ratio is significant. This conclusion is very important, as it allows the stability characteristics of the system iteration to be analyzed independently of specific trajectory. Figure 6 shows the eigenvalue magnitudes as a function of Mach number and angle of attack. One eigenvalue is always zero and has no effect on the stability of the system. The other eigenvalue has a nonzero magnitude and determines the convergence properties of the algorithm.

Subsonically, the nonzero eigenvalue is stable, but approaches neutral stability at Mach 1.0. This nearly neutral stability causes the algorithm to take a larger number of cycles to converge transonically. As presented in the Evaluation of the System Accuracy section, this slow convergence also causes the overall system accuracy to be somewhat degraded near Mach 1.0. For moderate supersonic Mach numbers, the eigenvalue magnitude drops rapidly and the algorithm again becomes stable. As the Mach number increases beyond Mach 4, the stability of the algorithm is reduced until eventually the iteration becomes unstable beyond Mach 8. The likely cause of this reduced stability is that equation $9($ b) has become so ill-conditioned that small changes in the ratio of $q_{c}$ to $P_{\infty}$ produce large changes in the free stream Mach number. Fortunately, below Mach 4, where airdata are required by the vehicle flight control system, iteration stability does not appear to be a problem.

\section{Algorithm Startup}

At very high Mach numbers, even though the $\alpha_{e}$ and $\beta_{e}$ solutions will still be valid, the stability problems presented in the last section require the iterative algorithm to be shutoff to avoid numerical divergence. When this algorithm shutoff is applied, a reliable method 
must be available for bringing the algorithm back on-line when the Mach number decreases back to safe limits. One approach relies on the use of inertial Mach number to initialize the algorithm. Another simple, but effective approach requires no outside information for initialization and is presented here. The method presented here was developed and flight tested by Whitmore, et al $^{6}$ (1995).

A block diagram of the startup algorithm is depicted in figure 7. A prescribed startup Mach number is preselected and hard-coded. For the X-33 trajectory the default startup Mach number is 4.0 . When the startup algorithm is initiated, the transducers are polled and an initial pressure data set (the target) is obtained. Using the target pressure set, $\alpha_{e}$ and $\beta_{e}$ are evaluated independently of Mach number using the triples algorithm. With the resulting values for $\alpha_{e}$ and $\beta_{e}$ and the target pressure data, the FADS algorithm iteration is used to compute a new estimate for static pressure, Mach number, impact pressure, and $\varepsilon$.

The aerodynamic model is then used to generate a predicted pressure distribution corresponding to the computed airdata set. The resulting biased pressure distribution is linearly perturbed toward the target set by a small increment (currently $1 / 100$ of the distance between the target set and the predicted pressure set). Using the perturbed value, a new estimate of the Mach number is evaluated using the FADS iterative algorithm. A new pressure prediction corresponding to the perturbed airdata state is evaluated and the progression along the line from the predicted pressures to the target pressures is repeated again until the target set is reached or the maximum number of increments have been performed.

\section{Calibration of the Aerodynamic Model}

There are three calibration parameters which must be evaluated for the X-33 FADS system: the position enror $(\varepsilon)$, the angle of attack flow correction angle $(\delta \alpha)$, and the angle of sideslip flow correction angle $(\delta \beta)$. For the preliminary design these calibration data were obtained from wind tunnel data. A two-percent model of the fullscale X-33 was instrumented with pressure taps corresponding to the desired X-33 locations and then tested over a wide Mach number, angle of attack, and angle of sideslip range. To obtain the preliminary calibrations, the model was tested in two NASA Langley wind tunnels (1) the 16-Foot wind tunnel ${ }^{21}$ and (2) the Unitary Plan wind tunnel (UPWT). ${ }^{22} \mathrm{~A}$ description of the test model, the test instrumentation, and the test conditions follows.

\section{X-33 Wind Tunnel Model and Test Instrumentation}

The two-percent X-33 model was manufactured for measuring total vehicle forces and moments and measuring nosecap surface pressures. The 21 nosecap surface pressures included the locations of the X-33 FADS ports and were used to determine the FADS aerodynamic calibrations. The wind tunnel model was machined from a solid piece of aluminum and the nose cone was made of stainless steel to minimize damage from tunnel contaminants. All FADS pressure ports were drilled normal to the surface with a diameter of 0.04 in.

The surface pressures were sensed through an electronically scanned pressure (ESP) module which produces a time-multiplexed analog output with up to 32 channels available for each module. The ESP was located approximately 5 in. aft of the nosecap and was plumbed to the various surface ports using flexible pneumatic tubing. Because of the short line lengths involved, pneumatic lag in the pressure tubing was considered negligible. The ESP sensor was $\mathrm{a} \pm 10 \mathrm{lb} / \mathrm{in}^{2}$ differential module with a manufacturers accuracy of better than \pm 0.1 percent of the full-scale reading. The time-multiplexed analog outputs from the ESP were tagged and sampled using a 16-bit analog-to-digital (AVD) conversion system.

During the wind tunnel tests, zero-shifts in the ESP module were frequently monitored and later applied to the data. Additionally, spare ESP ports were plumbed together to monitor the drift in the individual sensors in the ESP unit during the tests. If, for a particular test point, the drift rates were observed to be excessive, then the test point was repeated. Test points in which any ESP drift exceeded $2.0 \mathrm{lb} / \mathrm{ft}^{2}$ were not used. The reference pressure source for ESP was located outside of the wind tunnel and was sensed using a highly accurate absolute pressure transducer. The reference pressure transducer featured a capacitive transduction technology, with an accuracy of $\pm 0.25 \mathrm{lb} / \mathrm{ft}^{2}$. Outputs from the sensor were sampled using the 16-bit A/D system.

\section{Wind Tunnel Test Facilities and Test Conditions}

The Langley 16-foot wind tunnel is a closed-circuit, single-return, continuous-flow, atmospheric tunnel with a Mach number range from 0.2 to 1.3. The tunnel has an octagonal, $16 \mathrm{ft}$ slotted test section. Run limitations are often imposed near transonic Mach numbers because of the lack of porous walls that absorb reflected shock waves. The small size of the X-33 model, however, allowed Mach numbers of 0.95 and 1.05 without reflected shock wave interference. Angles of attack 
ranged from $-10^{\circ}$ to $24^{\circ}$ and angles of sideslip from $-10^{\circ}$ to $16^{\circ}$. Angle of sideslip sweeps were done at $0^{\circ}$ and $8^{\circ}$ angle of attack, and angle of attack sweeps were done at $-8^{\circ},-5^{\circ}, 0^{\circ}, 5^{\circ}$, and $8^{\circ}$ angles of sideslip.

The UPWT is a closed-circuit, continuous-flow, variable density supersonic wind tunnel with two $4 \times 4 \mathrm{ft}$ test sections. One test section has a Mach number range of 1.5 to 2.9 and the other has a range of 2.3 to approximately 4.5 . The angle of attack ranged from $-10^{\circ}$ to $26^{\circ}$ and angle of sideslip from $\pm 10^{\circ}$. Angle-ofsideslip sweeps were done at $0^{\circ}$ and $8^{\circ}$ angle of attack. Angle of attack sweeps were done at $-8^{\circ},-5^{\circ}, 0^{\circ}, 5^{\circ}$, and $8^{\circ}$ angles of sideslip. The Reynolds number was nearly constant at $2 \times 10^{6}$ per $\mathrm{ft}$. As with the previous 16-ft tunnel tests, runs were conducted with and without a grit ring installed aft of the FADS ports, with little variation in the pressure distribution observed.

Table 4 summarizes the ranges of conditions and configurations which were tested.

Table 4. Range of wind tunnel test conditions.

\begin{tabular}{cccc}
\hline \hline Tunnel & Mach range & $\begin{array}{c}\alpha, \\
\mathrm{deg}\end{array}$ & $\begin{array}{c}\beta, \\
\mathrm{deg}\end{array}$ \\
\hline \multirow{2}{*}{$16-\mathrm{ft}$} & 0.25 to & -10 to & -10 to \\
& 1.2 & 24 & 16 \\
UPWT & 1.6 to & -10 to & -10 to \\
& 4.50 & 26 & 10 \\
\hline \hline
\end{tabular}

\section{Evaluation of the FADS Calibration}

The calibration parameters were estimated from the wind tunnel data using measured pressures to estimate $\alpha_{e}$ and $\beta_{e}$ by means of the triples algorithm. Results for $\alpha_{e}$ and $\beta_{e}$ were used with wind tunnel reference conditions for $\mathrm{M}_{\infty}$ and $q_{c}$ to predict surface pressures at the measurement locations. The residuals between the predicted and measured pressures were then used to calculate $\varepsilon$ for each test point using linear regression. Finally, trends in the residuals were curve fit to produce the calibrations. A description of the three component parts of the calibration follows, in detail.

\section{Angle-of-Attack Calibration}

The angle-of-attack calibration relates the local angle of attack to the free stream value. Residuals between the wind tunnel reference conditions and the estimates for $\alpha_{e}$ were curve fit with third order polynomials in $\alpha_{e}$ to give the correction factor $(\delta \alpha)$. The coefficients of the fit were scheduled as a function of $\mathrm{M}_{\infty}$. The resulting calibration function is

$$
\begin{aligned}
\delta \alpha= & A_{0}\left[\mathrm{M}_{\infty}\right]+A_{1}\left[\mathrm{M}_{\infty}\right] \alpha_{e} \\
& +A_{2}\left[\mathrm{M}_{\infty}\right] \alpha_{e}^{2}+A_{3}\left[\mathrm{M}_{\infty}\right] \alpha_{e}^{3}
\end{aligned}
$$

The true angle of attack is evaluated by subtracting the correction factor $(\delta \alpha)$ from the indicated value. The calibration data and the corresponding curve fits for $\delta \alpha$ are presented as a function of Mach number in figure 8. The polynomial fits to the wind tunnel data are excellent. Also notice that the curves flatten out with increasing Mach number, a result of diminishing flow deflections at increasing Mach numbers.

\section{Angle-of-Sideslip Calibration}

In a manner identical to the angle-of-attack calibration, the angle-of-sideslip calibration relates the correction to the local angle of sideslip sensed by the FADS to the free stream value. The wind tunnel residual data were fit with third order polynomials in $\beta_{e}$ with the coefficients scheduled as a function of Mach number. The resulting calibration function is

$$
\begin{aligned}
\delta \beta= & B_{0}\left[\mathrm{M}_{\infty}\right]+B_{1}\left[\mathrm{M}_{\infty}\right] \beta_{e} \\
& +B_{2}\left[\mathrm{M}_{\infty}\right] \beta_{e}^{2}+B_{3}\left[\mathrm{M}_{\infty}\right] \beta_{e}^{3}
\end{aligned}
$$

The calibration data and the corresponding curve fits for $\delta \beta$ are presented in figure 9 .

\section{Position Error $(\varepsilon)$ Calibration}

The position error calibration parameter adjusts the FADS pressure model for changes in the incidence angle and Mach number. The wind tunnel data were curve fit with second order polynomials in angle of attack and angle of sideslip, and the coefficients scheduled as a function of Mach number. The resulting calibration model is

$$
\begin{aligned}
\varepsilon= & \varepsilon_{M}\left[M_{\infty}\right]+\varepsilon_{\alpha_{1}}\left[M_{\infty}\right] \alpha_{e}+\varepsilon_{\alpha_{1}}\left[M_{\infty}\right] \alpha_{e}^{2} \\
& +\varepsilon_{\beta_{1}}\left[M_{\infty}\right] \beta_{e}+\varepsilon_{\beta_{1}}\left[M_{\infty}\right] \beta_{e}^{2}
\end{aligned}
$$

The calibration curves for $\varepsilon$ at zero $\beta_{e}$ are presented in figure $10(a)$. The variations of $\varepsilon$ with $\beta_{e}$ at zero $\alpha_{e}$ are shown in figure $10(\mathrm{~b})$. The parameter $\varepsilon_{\mathrm{M}}$ (at zero $\alpha_{e}$ and $\beta_{e}$ ) is plotted as a function of the free stream Mach number in figure $10(\mathrm{c})$.

It is interesting to note that the trends shown in figures 10 (a) and 10 (b) are remarkably similar. In both figures, 10(a) and 10(b), the data form a family of parabolic curves. The peak of each parabola $\left(\varepsilon_{M}\right)$ increases in magnitude and shifts to increased angle of 
attack as Mach number increases. The curves in figures 10(a) and 10(b) have negative concavity subsonically, almost no concavity transonically, and positive concavity supersonically. Also, at close to supersonic Mach numbers, $\varepsilon_{M}$ approaches zero, an observation which confirms that the FADS flow model is consistent with modified Newtonian flow theory.

\section{Evaluation of the System Accuracy}

The accuracy of the calibrated FADS system was analyzed using an analysis-of-variance ${ }^{23}$ method. In this method, the calibrations for $\varepsilon, \delta \alpha$, and $\delta \beta$ and also the measured pressure distributions were used to generate airdata estimates with the FADS algorithm for each wind tunnel test point. Assuming that the measured wind tunnel reference conditions represent a truth set, quantitative measures of the overall system accuracy are a product of the residuals between FADS algorithm estimates and the wind tunnel reference conditions. The residuals include errors in the wind tunnel reference conditions, and are considered to be representative measures of the absolute system accuracy.

Note that the calibration curves were derived using only data from angle of attack sweeps at zero angle of sideslip and angle of sideslip sweeps at zero angle of attack. The error analysis, however, includes residual data that were obtained during test points which included both nonzero angle of attack and nonzero angle of sideslip.

Figure 11 shows the available wind tunnel database for angle of attack and Mach number and typical Michael Army Air Field (MAAF) and Malmstrom Air Force Base (MAFB) flight trajectories. Clearly, many of the wind tunnel points are far outside of the actual flight conditions to be encountered during the X-33 flight tests. Introducing these unrealistic data into the residual analysis would likely give error estimates which are too large. Thus, the following procedure was used to reduce the wind tunnel data sets to a more realistic and manageable size.

1. The outer boundaries of the minimum and maximum angles of attack and angles of sideslip to be encountered as a function of Mach number were determined for typical MAAF/MAFB launch and TAEM flight trajectories.

2. Next, the union of the outer boundaries was determined and $\pm 5^{\circ}$ angle of attack and $\pm 3^{\circ}$ angle of sideslip were added to give the domain space over which the residuals would be analyzed. This domain space allows for considerable variation away from the nominal trajectory.

3. All test points which exhibited more that $2.0 \mathrm{lb} / \mathrm{ft}^{2}$ of drift in the ESP readings were eliminated from the domain space.

4. Within this domain space, root-mean-square (RMS) averages of the residuals for the angle-ofattack and angle-of-sideslip test points were evaluated as a function of Mach number.

5. Finally, the resulting RMS averages were fared and tabulated as a function of Mach number to produce a set of three simple 1- $\sigma$ error models with Mach number as the independent variable, and $\delta \mathrm{M}, \delta \alpha$, and $\delta \beta$ outputs. Figure 12 displays these RMS enor estimates as a function of Mach number.

Figure 12(a) shows the percentage of Mach number error and the accuracy requirement for the X-33 FADS. The Mach error shows a sizable error jump at transonic speeds, but does not exceed the error limit. The angle-ofattack and angle-of-sideslip error plots are displayed with the accuracy requirements in figures 12 (b) and 12(c). Below Mach 4.0 the errors for both parameters are within the accuracy requirements of the X-33 airdata system.

Note that in examining figure 12 (a) in more detail, growth in the Mach number error percentage (both transonically and above Mach 2.5) corresponds closely to the growth in the nonzero eigenvalue (fig. 6). This result is not entirely surprising. The eigenvalues represent a measure of the numerical conditioning of the system. Transonically this numerical ill-conditioning is caused by the inflection point at which the flow switches from subsonic to supersonic. This inflection point corresponds to a point of maximum slope in the $\varepsilon_{\mathrm{M}}$ Mach number curve (fig. 10(c)). At supersonic speeds this ill-conditioning is caused by the rapid growth in the strength of the bow shock as Mach number increases. The result is that large changes in the free stream Mach number produce only small changes in the local pressure distribution. Conversely, small changes in the measured pressure distribution make for large changes in the estimated free stream Mach number. This illconditioning with respect to Mach number is an unavoidable consequence of the flow physics and is common to all airdata measurement systems at transonic and supersonic Mach numbers. 


\section{Summary and Concluding Remarks}

The X-33 FADS design is presented in this paper. The FADS concept, in which airdata are inferred from nonintrusive surface pressure measurements, does not require stagnation of the surface flow. This innovation extends the useful range of the airdata measurement system to the hypersonic flow regime. The FADS system uses a matrix of pressure orifices on the vehicle nose to estimate airdata parameters.

The FADS system design exploits the built-in redundancy in the pressure port matrix to achieve FailOp capability with only dual redundancy in the system hardware. The design produces two independent measurement paths for the airdata and the redundancy management scheme selects the measurement path with the best overall fit consistency. This scheme allows for failure, either detected or undetected, to occur anywhere in the system without degrading the overall performance.

Presented here is the aerodynamic model that relates the airdata parameters to the measured pressures. Also presented is the derivation of the estimating algorithm. The mathematical properties of the algorithm were analyzed in detail. At near hypersonic Mach numbers, the stability of the algorithm is reduced because the bow shock wave has become so strong that small disturbances are highly amplified. Eventually the iteration becomes unstable, at close to Mach 8 and beyond. This illconditioning with respect to Mach number is an unavoidable consequence of the flow physics. Fortunately, below Mach 4, where airdata are required for the vehicle flight control system, potential mathematical singularities and iterative instabilities in the nonlinear estimating algorithm can be prevented by using simple logic.

Because of the problems with stability at high supersonic Mach numbers, the iterative algorithm must be shutoff in order to avoid numerical divergence problems. A reliable method for bringing the algorithm back on-line was presented. This simple creeping solution method insures that the algorithm does not exceed the small perturbation limits of the stability analysis.

There are three calibration parameters which must be evaluated for the X-33 FADS system: the position error $(\varepsilon)$, the angle of attack flow correction $(\delta \alpha)$, and the angle of sideslip flow correction $(\delta \beta)$. For the preliminary X-33 design these data were evaluated from wind tunnel calibrations. A two-percent full-scale X-33 model was instrumented and tested over a variety of angles of attack and Mach number ranges in two separate wind tunnels. Data were obtained for Mach numbers ranging from 0.25 to 4.5 , angles of attack from $-10^{\circ}$ to $25^{\circ}$, and angles of sideslip from $\pm 10^{\circ}$ to $16^{\circ}$.

The accuracy of the system was evaluated by applying the calibrations and the FADS algorithm to generate airdata estimates for each wind tunnel test point using the measured pressure distribution. Assuming that the wind tunnel reference conditions represented a truth set, the statistical accuracy was evaluated by computing residuals between the reference set and FADS estimates and then compiling the results into a set of 1- $\sigma$ error models. The error analysis concluded that the FADS meets the accuracy requirements for the $\mathrm{X}-33$ vehicle.

\section{Appendix: Mathematical Analysis of the Flush Airdata Sensing Algorithm}

As discussed in the main text, the airdata states are related to the surface pressures by an aerodynamic model that captures salient features of the flow, and is valid over a very large Mach number range. The resulting model takes the form

$$
p_{i}=q_{c}\left[\cos ^{2}\left(\theta_{i}\right)+\varepsilon \sin ^{2}\left(\theta_{i}\right)\right]+P_{\infty}
$$

where

$$
\begin{aligned}
\cos \left(\theta_{i}\right)= & \cos \left(\alpha_{e}\right) \cos \left(\beta_{e}\right) \cos \left(\lambda_{i}\right) \\
& +\sin \left(\beta_{e}\right) \sin \left(\phi_{i}\right) \sin \left(\lambda_{i}\right) \\
& +\sin \left(\alpha_{e}\right) \cos \left(\beta_{e}\right) \cos \left(\phi_{i}\right) \sin \left(\lambda_{i}\right)
\end{aligned}
$$

Defining the terms

$$
\begin{aligned}
& a_{i}=\cos \alpha_{e} \cos \lambda_{i}+\sin \alpha_{e} \sin \lambda_{i} \cos \phi_{i} \\
& b_{i}=\sin \lambda_{i} \sin \phi_{i}
\end{aligned}
$$

equation $A-2$ reduces to

$$
\cos \left(\theta_{i}\right)=a_{i} \cos \left(\beta_{e}\right)+b_{i} \sin \left(\beta_{e}\right)
$$

\section{The Triples Formulation}

Using equation A-1 to take strategic combinations of three pressures (triples) the impact pressure, static pressure, and calibration parameter are decoupled from the local angle of attack and angle of sideslip. 


$$
\begin{array}{r}
\frac{p_{i}-p_{j}}{p_{j}-p_{k}}=\left[\begin{array}{c}
q_{c}\left\{\cos ^{2} \theta_{i}+\varepsilon \sin ^{2} \theta_{i}\right\}+P_{\infty} \\
-\left[q_{c}\left\{\cos ^{2} \theta_{j}+\varepsilon \sin ^{2} \theta_{j}\right\}+P_{\infty}\right] \\
q_{c}\left\{\cos ^{2} \theta_{j}+\varepsilon \sin ^{2} \theta_{j}\right\}+P_{\infty} \\
-\left[q_{c}\left\{\cos ^{2} \theta_{k}+\varepsilon \sin ^{2} \theta_{k}\right\}+P_{\infty}\right]
\end{array}\right] \\
\left\{\frac{\left\{(1-\varepsilon) \cos ^{2} \theta_{i}+\varepsilon\right\}-\left\{(1-\varepsilon) \cos ^{2} \theta_{j}+\varepsilon\right\}}{\left\{(1-\varepsilon) \cos ^{2} \theta_{j}+\varepsilon\right\}-\left\{(1-\varepsilon) \cos ^{2} \theta_{k}+\varepsilon\right\}}\right. \\
=\frac{\cos ^{2} \theta_{i}-\cos ^{2} \theta_{j}}{\cos ^{2} \theta_{j}-\cos ^{2} \theta_{k}}
\end{array}
$$

\section{Expanding equation $\mathrm{A}-5$ and defining}

$$
\Gamma_{i k} \equiv p_{i}-p_{k}, \Gamma_{j i} \equiv p_{j}-p_{i}, \Gamma_{k j} \equiv p_{k}-p_{j}
$$

equation $A-5$ reduces to

$$
\Gamma_{i k} \cos ^{2} \theta_{j}+\Gamma_{j i} \cos ^{2} \theta_{k}+\Gamma_{k j} \cos ^{2} \theta_{i}=0
$$

Substituting in from equation $A-4$, dividing by $\cos ^{2} \beta\left(\beta \neq \pm 90^{\circ}\right)$ and collecting terms, equation A-7 becomes

$$
\begin{aligned}
& \Gamma_{i k}\left[a_{j}+b_{j} \tan \beta\right]^{2}+\Gamma_{j i}\left[a_{k}+b_{k} \tan \beta\right]^{2} \\
& +\Gamma_{k j}\left[a_{i}+b_{i} \tan \beta\right]^{2}=0
\end{aligned}
$$

In equation A-8, the local angle of attack and angle of sideslip have been written as a function of the measured pressure only, the impact pressure, $\varepsilon$, and static pressure have been decoupled.

\section{Angle of Attack Solution}

Angle of attack is decoupled from angle of sideslip using a meridian solution, in which, along the vertical meridian $\phi=0, \pm 180^{\circ}$, and equation A-8 reduces to

$$
\begin{aligned}
& \Gamma_{i k}\left[\cos \alpha \cos \lambda_{j}+\sin \alpha \sin \lambda_{j} \cos \phi_{j}\right]^{2} \\
& +\Gamma_{j i}\left[\cos \alpha \cos \lambda_{k}+\sin \alpha \sin \lambda_{k} \cos \phi_{k}\right]^{2} \\
& +\Gamma_{k j}\left[\cos \alpha \cos \lambda_{i}+\sin \alpha \sin \lambda_{i} \cos \phi_{i}\right]^{2}=0
\end{aligned}
$$

Factoring $\cos \alpha\left(\alpha \neq \pm 90^{\circ}\right)$ out of equation $A-9$,

$$
\begin{aligned}
& \Gamma_{i k}\left[\cos \lambda_{j}+\tan \alpha \sin \lambda_{j} \cos \phi_{j}\right]^{2} \\
& +\Gamma_{j i}\left[\cos \lambda_{k}+\tan \alpha \sin \lambda_{k} \cos \phi_{k}\right]^{2} \\
& +\Gamma_{k j}\left[\cos \lambda_{i}+\tan \alpha \sin \lambda_{i} \cos \phi_{i}\right]^{2}=0
\end{aligned}
$$

Expanding the squares, the result is a quadratic expression in $\tan \alpha$,

$$
\begin{aligned}
& {\left[\Gamma_{i k} \sin ^{2} \lambda_{j}+\Gamma_{j i} \sin ^{2} \lambda_{k}+\Gamma_{k j} \sin ^{2} \lambda_{i}\right] \tan ^{2} \alpha} \\
& +2\left[\Gamma_{i k} \cos \lambda_{j} \sin \lambda_{j} \cos \phi_{j}+\Gamma_{j i} \cos \lambda_{k} \sin \lambda_{k} \cos \phi_{k}\right. \\
& \left.+\Gamma_{k j} \cos \lambda_{i} \sin \lambda_{i} \cos \phi_{i}\right] \tan \alpha \\
& +\left[\Gamma_{i k} \cos ^{2} \lambda_{j}+\Gamma_{j i} \cos ^{2} \lambda_{k}+\Gamma_{k j} \cos ^{2} \lambda_{i}\right]=0
\end{aligned}
$$

Equation A-11 can be reduced further by noting that $\cos ^{2} \lambda=1-\sin ^{2} \lambda$ and

$$
\begin{aligned}
\Gamma_{i k} \cos ^{2} \lambda_{j}+\Gamma_{j i} \cos ^{2} \lambda_{k}+\Gamma_{k j} \cos ^{2} \lambda_{i} \\
=\Gamma_{i k}\left(1-\sin ^{2} \lambda_{j}\right)+\Gamma_{j i}\left(1-\sin ^{2} \lambda_{k}\right) \\
+\Gamma_{k j}\left(1-\sin ^{2} \lambda_{i}\right)=\Gamma_{i k}+\Gamma_{j i}+\Gamma_{k j} \\
-\left(\Gamma_{i k} \sin ^{2} \lambda_{j}+\Gamma_{j i} \sin ^{2} \lambda_{k}+\Gamma_{k j} \sin ^{2} \lambda_{i}\right) \\
=\left(p_{i}-p_{k}\right)+\left(p_{j}-p_{i}\right)+\left(p_{k}-p_{j}\right) \\
-\left(\Gamma_{i k} \sin ^{2} \lambda_{j}+\Gamma_{j i} \sin ^{2} \lambda_{k}+\Gamma_{k j} \sin ^{2} \lambda_{i}\right) \\
=-\left(\Gamma_{i k} \sin ^{2} \lambda_{j}+\Gamma_{j i} \sin ^{2} \lambda_{k}+\Gamma_{k j} \sin ^{2} \lambda_{i}\right)
\end{aligned}
$$

Substituting equation A-12 into equation A-11,

$$
\begin{aligned}
& {\left[\Gamma_{i k} \sin ^{2} \lambda_{j}+\Gamma_{j i} \sin ^{2} \lambda_{k}+\Gamma_{k j} \sin ^{2} \lambda_{i}\right]\left[\tan ^{2} \alpha-1\right]} \\
& +2\left[\Gamma_{i k} \cos \lambda_{j} \sin \lambda_{j} \cos \phi_{j}\right. \\
& +\Gamma_{j i} \cos \lambda_{k} \sin \lambda_{k} \cos \phi_{k} \\
& \left.+\Gamma_{k j} \cos \lambda_{i} \sin \lambda_{i} \cos \phi_{i}\right] \tan \alpha=0
\end{aligned}
$$


Defining

$$
\begin{aligned}
A= & \left(\Gamma_{i k} \sin ^{2} \lambda_{j}+\Gamma_{j i} \sin ^{2} \lambda_{k}+\Gamma_{k j} \sin ^{2} \lambda_{i}\right) \\
B= & \left(\Gamma_{i k} \cos \phi_{j} \sin \lambda_{j} \cos \lambda_{j}\right. \\
& \left.+\Gamma_{j i} \cos \phi_{k} \sin \lambda_{k} \cos \lambda_{k}+\Gamma_{k j} \cos \phi_{i} \sin \lambda_{i} \cos \lambda_{i}\right)
\end{aligned}
$$

Equation $\mathrm{A}-14$ is written in the simple form

$$
A\left[\tan ^{2} \alpha-1\right]+2 B \tan \alpha=0
$$

The correct solution is extracted from equation A-15 by noting that

$$
\begin{aligned}
\tan ^{2} \alpha-1 & =\frac{\sin ^{2} \alpha-\cos ^{2} \alpha}{\cos ^{2} \alpha} \\
& =\frac{1-2 \cos ^{2} \alpha}{\cos ^{2} \alpha}=-\frac{\cos 2 \alpha}{\cos ^{2} \alpha}
\end{aligned}
$$

Substituting equation A-16 into equation A-15, and multiplying through by $\cos ^{2} \alpha$,

$$
\begin{aligned}
& -A \cos 2 \alpha+2 B \cos \alpha \sin \alpha \\
& =-A \cos 2 \alpha+B \sin 2 \alpha=0
\end{aligned}
$$

and the solution for $\alpha$ is

$$
\alpha=\frac{1}{2} \tan ^{-1}\left[\frac{A}{B}\right]
$$

For $|\alpha| \leq 45^{\circ}$, equation A-18 picks the correct root; when $|\alpha|>45^{\circ}$ then the correct root is given by the complement of equation A-18

$$
\alpha=\frac{1}{2}\left(\pi-\tan ^{-1}\left[\frac{A}{B}\right]\right)
$$

\section{Angle of Sideslip Solution}

Given the solution for angle of attack, a procedure similar to that of the previous section is followed for angle of sideslip. Expanding the squares in equation A-7 and solving for like terms in $\tan \beta$,

$$
\begin{aligned}
& {\left[\Gamma_{i k} b_{j}^{2}+\Gamma_{j i} b_{k}^{2}+\Gamma_{k j} b_{i}^{2}\right] \tan ^{2} \beta} \\
& +2\left[\Gamma_{i k} a_{j} b_{j}+\Gamma_{j i} a_{k} b_{k} c+\Gamma_{k j} a_{i} b_{i}\right] \tan \beta \\
& +\Gamma_{i k} a_{j}^{2}+\Gamma_{j i} a_{k}^{2}+\Gamma_{k j} a_{i}^{2}=0
\end{aligned}
$$

Defining

$$
\begin{aligned}
& A^{\prime}=\left(\Gamma_{i k} b_{j}{ }^{2}+\Gamma_{j i} b_{k}{ }^{2}+\Gamma_{k j} b_{i}{ }^{2}\right) \\
& B^{\prime}=\left(\Gamma_{i k} a_{j} b_{j}+\Gamma_{j i} a_{k} b_{k}+\Gamma_{k j} a_{i} b_{i}\right) \\
& C^{\prime}=\left(\Gamma_{i k} a_{j}{ }^{2}+\Gamma_{j i} a_{k}{ }^{2}+\Gamma_{k j} a_{i}{ }^{2}\right)
\end{aligned}
$$

Equation A-20 reduces to a quadratic equation in $\tan \beta$

$$
A^{\prime} \tan ^{2} \beta+2 B^{\prime} \tan \beta+C^{\prime}=0
$$

The two solutions to equation A-22 are

$$
\tan \beta_{1}, \tan \beta_{2}=-\left[\frac{B^{\prime}}{A^{\prime}}\right] \pm \sqrt{\left[\frac{B^{\prime}}{A^{\prime}}\right]^{2}-\left[\frac{C}{A^{\prime}}\right]}
$$

\section{Root Selection Criteria for Angle of Sideslip}

The relationship of $\tan \left[\beta_{1}\right]$ to $\tan \left[\beta_{2}\right]$ is developed by taking the product of the roots

$$
\begin{array}{r}
\tan \beta_{1} \tan \beta_{2}=\left(-\left[\frac{B^{\prime}}{A^{\prime}}\right]+\sqrt{\left[\frac{B^{\prime}}{A^{\prime}}\right]^{2}-\left[\frac{C^{\prime}}{A^{\prime}}\right]}\right) \\
\times\left(-\left[\frac{B^{\prime}}{A^{\prime}}\right]-\sqrt{\left.\left[\frac{B^{\prime}}{A^{\prime}}\right]^{2}-\left[\frac{C}{A^{\prime}}\right]\right)}=\frac{C}{A^{\prime}}\right.
\end{array}
$$

Rearranging equation A-24 gives the relationship of the two roots

$$
\tan \beta_{1}=\frac{C}{A^{\prime}}\left(\frac{1}{\tan \beta_{2}}\right)=\frac{C^{\prime}}{A^{\prime}} \tan \left(\frac{\pi}{2}-\beta_{2}\right)
$$

For several specific port arrangements relevant to the X-33 design, the relationship between the two roots can be written in closed form. Three of these special arrangements will now be discussed.

\section{Root Selection Criteria for the Triples on Lateral} Meridian

Along the lateral angle-of-sideslip meridian, the outer port clock angles are $\pm 90^{\circ}$, and $a_{i j k}=\cos \alpha \cos \lambda_{i j k}, b_{i j k}= \pm \sin \lambda_{i j k}$, thus equation A-24 reduces to 


$$
\begin{aligned}
{\left[\frac{C}{A^{\prime}}\right] } & =\frac{\Gamma_{i k} a_{j}^{2}+\Gamma_{j i} a_{k}^{2}+\Gamma_{k j} a_{i}^{2}}{\Gamma_{i k} b_{j}^{2}+\Gamma_{j i} b_{k}^{2}+\Gamma_{k j} b_{i}^{2}} \\
& =\cos ^{2} \alpha\left(\frac{\Gamma_{i k} \cos ^{2} \lambda_{j}+\Gamma_{j i} \cos ^{2} \lambda_{k}+\Gamma_{k j} \cos ^{2} \lambda_{i}}{\Gamma_{i k} \sin ^{2} \lambda_{j}+\Gamma_{j i} \sin ^{2} \lambda_{k}+\Gamma_{k j} \sin ^{2} \lambda_{i}}\right) \\
& =-\cos ^{2} \alpha
\end{aligned}
$$

Thus, along the lateral meridian the relationship between the two solutions of equation A-22 is

$$
\tan \beta_{1}=\cos ^{2} \alpha \tan \left[\beta_{2}-\frac{\pi}{2}\right]
$$

The solution for $\beta_{2}$ is plotted as a function of $\beta_{1}$ and the local angle of attack in figure A-1. Even for angles of attack as high as $50^{\circ}$ the two angles of sideslip solutions are nearly $70^{\circ}$ out of phase; so for triples along the lateral meridian, selecting the root with $|\beta|$ closest to zero will always produce the correct solution for $\beta$.

\section{Off-Meridian Triples, Symmetric Arrangement}

Assume ports $i$ and $j$ lie on the lateral meridian and port $k$ lies on the vertical meridian, then

$$
\begin{aligned}
\phi_{i}=\frac{\pi}{2} \Rightarrow a_{i} & =\cos \alpha \cos \lambda_{i} \\
b_{i} & =\sin \lambda_{i} \\
\phi_{j}=\frac{\pi}{2} \Rightarrow a_{j} & =\cos \alpha \cos \lambda_{j} \\
b_{j} & =-\sin \lambda_{j} \\
\phi_{k}=0 \Rightarrow a_{k} & =\cos \alpha \cos \lambda_{k}+\sin \alpha \sin \lambda_{k} \\
b_{k} & =0
\end{aligned}
$$

and for a symmetric arrangement, $\lambda_{i}=\lambda_{j}$, and $\frac{C}{A^{\prime}}$ reduces to

$$
\begin{aligned}
& \frac{C^{\prime}}{A^{\prime}}=\cos ^{2} \alpha \\
& \times\left[\frac{\cos \lambda_{j}{ }^{2}\left(\Gamma_{i k}+\Gamma_{k j}\right)+\Gamma_{j i}\left(\cos \lambda_{k}+\tan \alpha \sin \lambda_{k}\right)^{2}}{\sin ^{2} \lambda_{j}\left(\Gamma_{i k}+\Gamma_{k j}\right)}\right]
\end{aligned}
$$

Noting that $\Gamma_{i k}+\Gamma_{k j}=-\Gamma_{j i} \Rightarrow$ equation A-29 can be reduced further

$$
\begin{aligned}
\frac{C}{A^{\prime}}= & \cos ^{2} \alpha \\
& \times\left[\frac{-\Gamma_{j i} \cos \lambda_{j}{ }^{2}+\Gamma_{j i}\left(\cos \lambda_{k}+\tan \alpha \sin \lambda_{k}\right)^{2}}{-\Gamma_{j i} \sin ^{2} \lambda_{j}}\right] \\
= & \frac{\cos ^{2} \alpha}{\sin ^{2} \lambda_{j}}\left[\cos \lambda_{j}{ }^{2}-\frac{1}{\cos ^{2} \alpha}\left(\cos \alpha \cos \lambda_{k}+\sin \alpha \sin \lambda_{k}\right)^{2}\right] \\
= & \frac{\cos ^{2} \alpha \cos \lambda_{j}{ }^{2}-\cos ^{2}\left(\alpha-\lambda_{k}\right)}{\sin ^{2} \lambda_{j}}
\end{aligned}
$$

Substituting equation A-30 into equation A-25, the relationship between the two roots becomes

$$
\begin{aligned}
\tan \beta_{1}= & {\left[\frac{\cos ^{2} \alpha \cos \lambda_{j}^{2}-\cos ^{2}\left(\alpha-\lambda_{k}\right)}{\sin ^{2} \lambda_{j}}\right] } \\
& \times \tan \left[\frac{\pi}{2}-\beta_{2}\right]
\end{aligned}
$$

For the $\mathrm{X}-33$ design, there are two possible symmetric off-meridian angle of sideslip triples combinations,

$$
\begin{aligned}
& \left\{\lambda_{i}, \lambda_{j}, \lambda_{k}\right\}=\left\{20^{\circ}, 20^{\circ}, 45^{\circ}\right\}, \text { and } \\
& \left\{\lambda_{i}, \lambda_{j}, \lambda_{k}\right\}=\left\{20^{\circ}, 20^{\circ}, 20^{\circ}\right\}
\end{aligned}
$$

For the first set of coordinates $\left\{\lambda_{i}, \lambda_{j}, \lambda_{k}\right\}=$ $\left\{20^{\circ}, 20^{\circ}, 45^{\circ}\right\}$ the solution for $\beta_{2}$ is ploted as a function of $\beta_{1}$ and the local angle of attack in figure A-2(a). Notice that as $\alpha$ approaches 18.207\%, the angle of attack at which all of the incidence angles are equal, a singularity exists at $\beta=0$. Thus, for angles of attack near $18.207^{\circ}$, and angles of sideslip values near zero, the system is highly ill-conditioned. This illconditioning makes selecting the correct root impossible. Figure A-2(b) presents the same analysis as figure A-2(a), except now the second set of coordinates $\left\{\lambda_{i}, \lambda_{j}, \lambda_{k}\right\}=\left\{20^{\circ}, 20^{\circ}, 20^{\circ}\right\}$ is used. A singularity now exists when $\alpha=0^{\circ}$ and $\beta=0^{\circ}$.

Clearly, using the $\lambda_{k}=45^{\circ}$ port is the preferable choice for the off-lateral meridian. If one assumes that true angle-of-sideslip limits to be experienced are less than $\pm 20^{\circ}$, then for $\alpha \leq 17^{\circ}$, and $\alpha \geq 20^{\circ}$, a root-closestto-zero criterion is valid for selecting the correct root. For values of $\alpha$ between $17^{\circ}$ and $20^{\circ}$, the $\lambda_{\{i j k\}}=\left\{20^{\circ}, 20^{\circ}, 45^{\circ}\right\}$ system is indeterminate, and 
instead the $\lambda_{\{i j k\}}=\left\{20^{\circ}, 20^{\circ}, 20^{\circ}\right\}$ triple is used. With this substitution then, a root-closest-to-zero criterion always selects the correct root.

\section{Qff-Meridian Triples, Asymmetric Arrangement}

The root locations for one special case asymmetric port arrangement can be analyzed, that is the arrangement where $\lambda_{j}=0$. Consider the case where,

$$
\begin{aligned}
& \phi_{i}= \pm \frac{\pi}{2} \Rightarrow a_{i}= \cos \alpha \cos \lambda_{i} \\
& b_{i}= \pm \sin \lambda_{i} \\
& \phi_{j}=0, \lambda_{j}=0 \Rightarrow a_{j}=\cos \alpha \\
& b_{j}=0 \\
& \phi_{k}=0 \Rightarrow a_{k}=\cos \alpha \cos \lambda_{k}+\sin \alpha \sin \lambda_{k} \\
&=\cos \left(\alpha-\lambda_{k}\right) \\
& b_{k}=0
\end{aligned}
$$

Following the same procedures as before,

$$
\begin{gathered}
\frac{C}{A^{\prime}}= \\
\frac{\Gamma_{i k} \cos ^{2} \alpha+\Gamma_{j i} \cos ^{2}\left(\alpha-\lambda_{k}\right)+\Gamma_{k j} \cos ^{2} \alpha \cos ^{2} \lambda_{i}}{\Gamma_{k j} \sin ^{2} \lambda_{i}}
\end{gathered}
$$

Factoring out $\cos ^{2} \alpha$

$$
\begin{aligned}
\frac{C}{A^{\prime}} & =\cos ^{2} \alpha\left\{\frac{\Gamma_{i k}+\Gamma_{j i} \frac{\cos ^{2}\left(\alpha-\lambda_{k}\right)}{\cos ^{2} \alpha}+\Gamma_{k j} \cos ^{2} \lambda_{i}}{\Gamma_{\mathrm{kj}} \sin ^{2} \lambda_{i}}\right\} \\
& =\cos ^{2} \alpha\left\{\frac{\Gamma_{i k}+\Gamma_{j i} \frac{\cos ^{2}\left(\alpha-\lambda_{k}\right)}{\cos ^{2} \alpha}+\Gamma_{k j}\left(1-\sin ^{2} \lambda_{i}\right)}{\Gamma_{k j} \sin ^{2} \lambda_{i}}\right\}
\end{aligned}
$$

Collecting terms, equation $\mathrm{A}-35$ reduces to
$\frac{C}{A^{\prime}}=\cos ^{2} \alpha$

$$
\times\left\{\frac{\left(\Gamma_{i k}+\Gamma_{k j}\right)+\Gamma_{j i} \frac{\cos ^{2}\left(\alpha-\lambda_{k}\right)}{\cos ^{2} \alpha}-\Gamma_{k j}\left(\sin ^{2} \lambda_{i}\right)}{\Gamma_{k j}\left(\sin ^{2} \lambda_{i}\right)}\right\}
$$$$
=\cos ^{2} \alpha\left\{\frac{\Gamma_{i j}+\Gamma_{j i} \frac{\cos ^{2}\left(\alpha-\lambda_{k}\right)}{\cos ^{2} \alpha}-\Gamma_{k j}\left(\sin ^{2} \lambda_{i}\right)}{\Gamma_{k j} \sin ^{2} \lambda_{i}}\right\}
$$

$$
=\cos ^{2} \alpha\left\{\frac{\Gamma_{j i}}{\Gamma_{k j}} \frac{\left(\frac{\cos ^{2}\left(\alpha-\lambda_{k}\right)}{\cos ^{2} \alpha}-1\right)}{\sin ^{2} \lambda_{i}}-1\right\}
$$

The pressure dependent term, $\frac{\Gamma_{j i}}{\Gamma_{k j}}$, can be removed from equation A-34 by substituting in from equation A-5. Defining

$$
\Psi \equiv \frac{\left[\frac{\cos ^{2}\left(\alpha-\lambda_{k}\right)}{\cos ^{2} \alpha}-1\right]}{\sin \lambda_{i}^{2}}
$$

then equation $\mathrm{A}-37$ reduces to

$$
\frac{C}{A^{\prime}}=\cos ^{2} \alpha\left[\frac{\Gamma_{j i}}{\Gamma_{k j}} \Psi-1\right]
$$

and finally

$$
\tan \beta_{1}=\cos ^{2} \alpha\left[\frac{\Gamma_{j i}}{\Gamma_{k j}} \Psi-1\right] \tan \left[\frac{\pi}{2}-\beta_{2}\right]
$$

For the X-33 design, there are four possible asymmetric off-meridian angle of sideslip triples combinations, 


$$
\begin{aligned}
& \left\{\left[\lambda_{i}, \phi_{i}\right],\left[\lambda_{j}, \phi_{j}\right],\left[\lambda_{k}, \phi_{k}\right]\right\} \\
& =\left\{\left[20^{\circ}, \pm 90^{\circ}\right],\left[0^{\circ}, 0^{\circ}\right],\left[45^{\circ}, 0^{\circ}\right]\right\}
\end{aligned}
$$

and

$$
\begin{aligned}
& \left\{\left[\lambda_{i}, \phi_{i}\right],\left[\lambda_{j}, \phi_{j}\right],\left[\lambda_{k}, \phi_{k}\right]\right\} \\
& =\left\{\left[20^{\circ}, \pm 90^{\circ}\right],\left[0^{\circ}, 0^{\circ}\right],\left[20^{\circ}, 0^{\circ}\right]\right\}
\end{aligned}
$$

For the first sets of coordinates $\left\{\left[\lambda_{i}, \phi_{i}\right]\right.$, $\left.\left[\lambda_{j}, \phi_{j}\right],\left[\lambda_{k}, \phi_{k}\right]\right\}=\left\{\left[20^{\circ}, \pm 90^{\circ}\right],\left[0^{\circ}, 0^{\circ}\right],\left[45^{\circ}, 0^{\circ}\right]\right\}$ the solutions for $\beta_{2}$ are plotted as a function of $\beta_{1}$ and the local angle of attack in figure A-3(a). In the range of $|\beta|<25^{\circ}$, it is interesting to note that the second solution is nearly independent of the value of the first solution. For $\phi_{1}=90^{\circ}, \beta_{2} \cong-80^{\circ}$, and $\phi_{i}=-90^{\circ}, \beta_{2} \cong$ $80^{\circ}$.

Figure A-3(b) presents similar results for the $\beta_{2}$ solutions for the second set of coordinates $\left\{\left[\lambda_{i}, \phi_{i}\right]\right.$, $\left.\left[\lambda_{j}, \phi_{j}\right],\left[\lambda_{k}, \phi_{k}\right]\right\}=\left\{\left[20^{\circ}, \pm 90^{\circ}\right],\left[0^{\circ}, 0^{\circ}\right],\left[20^{\circ}, 0^{\circ}\right]\right\}$. Again, in the range of $|\beta|<25^{\circ}$, it is very interesting to note that $\beta_{2}$ is identical to the value produced by the previous set of coordinates $\left(\lambda_{k}=45^{\circ}\right)$. Clearly, the terms involving $\lambda_{k}$ are canceled out of equation A-38. As a result, for the asymmetric configuration a root-closestto-zero criterion will always select the correct solution.

\section{Angle-of-Sideslip Solution Summary}

The quadratic equation, A-22, has two roots, with no guarantees that they be in general orthogonal. However, several conclusions can be reached for special geometry arrangements which X-33 exploits in its design. These conclusions are:

1. For triples which lie on the lateral meridian, the solutions are nearly orthogonal, and for $|\beta|<25^{\circ}$, using a root-closest-to-zero selection criterion will always select the correct solution.

2. For off-meridian triples arrangements, only the symmetric arrangement presents a problem. For this arrangement, there exists a singularity point at which all three incidence angles are equal. In the vicinity of this singularity, the system is highly illconditioned. This ill-conditioning makes the system indeterminate and selecting the correct root is impossible without prior information.
3. For the $\mathrm{X}-33$ configuration, using the lower $45^{\circ}$ port to complete the symmetric triple puts the singularity at $18.207^{\circ}$ local angle of attack. Using the lower $20^{\circ}$ port puts the singularity at $0^{\circ}$ local angle of attack.

4. If one assumes that true angle-of-sideslip limits, to be experienced, are less than $\pm 25^{\circ}$, then for the $\lambda_{\{i j k\}}=\left\{20^{\circ}, 20^{\circ}, 45^{\circ}\right\}$ triple, for $\alpha \leq 17^{\circ}$, $a \geq 20^{\circ}$, a root-closest-to-zero criterion is valid for selecting the correct root. For values of $\alpha$ between $17^{\circ}$ and $20^{\circ}$, the $\lambda_{\{i j k\}}=\left\{20^{\circ}, 20^{\circ}, 45^{\circ}\right\}$ system should be considered indeterminate, and the $\lambda_{\{i j k\}}=\left\{20^{\circ}, 20^{\circ}, 20^{\circ}\right\}$ triple should be used instead. If this substitution is made, then a rootclosest-to-zero criterion will always be valid for selecting the correct root.

5. For the asymmetric off-meridian configuration, the alternate $\beta$ solution will always hover around $\pm 80^{\circ}$. Thus the root-closest-to-zero criterion is always valid.

\section{Static Pressure. Impact Pressure, and Mach Number}

\section{$\underline{\text { Solution }}$}

Once the local values of $\alpha$ and $\beta$ have been solved for, then the incidence angles at all of the ports can be evaluated, and only $\varepsilon, P_{\infty}$, and $q_{c}$ remain as unknowns in the pressure equations. Assuming that $n$ pressure measurements are to be used, the original model (eq. A-1) can be written in matrix form with static and impact pressure broken out as variables:

$$
\left[\begin{array}{c}
p_{1} \\
\cdot \\
\cdot \\
\cdot \\
p_{n}
\end{array}\right]=\left[\begin{array}{cc}
\left(\begin{array}{cc}
\cos ^{2}\left(\theta_{1}\right)+ \\
\varepsilon \sin ^{2}\left(\theta_{1}\right)
\end{array}\right) & \mathrm{I} \\
\cdot & \cdot \\
\cdot & \cdot \\
\left(\cos ^{2}\left(\theta_{n}\right)+\right. \\
\varepsilon \sin ^{2}\left(\theta_{n}\right)
\end{array}\right]\left[\begin{array}{c}
q_{c} \\
P_{\infty}
\end{array}\right]
$$

Ignoring for now, the fact that $\varepsilon$ is implicitly a function of static and impact pressure, equation A-42 can be solved for the static and impact pressure using weighted linear regression. ${ }^{19}$ The result is 


$$
\begin{aligned}
& {\left[\frac{\hat{q}_{c}}{\hat{P}_{\infty}}\right]} \\
& =\frac{\left[\begin{array}{cc}
\sum_{i=1}^{n} q_{i} & -\sum_{i=1}^{n} q_{i}\left(\Omega_{i}\right) \\
-\sum_{i=1}^{n} q_{i}\left(\Omega_{i}\right) & \sum_{i=1}^{n} q_{i}\left(\Omega_{i}\right)^{2}
\end{array}\right]\left[\begin{array}{c}
\sum_{i=1}^{n}\left(\Omega_{i}\right) q_{i} P_{i} \\
\sum_{i=1}^{n} q_{i} P_{i}
\end{array}\right]}{\left[\sum_{i=1}^{n} q_{i}\right]\left[\sum_{i=1}^{n} q_{i}\left(\Omega_{i}\right)^{2}\right]-\left[\sum_{i=1}^{n} q_{i}\left(\Omega_{i}\right)\right]^{2}}
\end{aligned}
$$

where $\Omega_{i}=\cos ^{2}\left(\theta_{i}\right)+\varepsilon \sin ^{2}\left(\theta_{i}\right)$. In equation $A-43$, the $q_{i}$ 's are weights which have a nominal value of 1.0 . Setting the value of $q_{i}$ to zero, weights the $i$ th pressure reading out of the algorithm. Equation A-43 looks like a closed form solution, but the $\varepsilon$ terms on the right-hand side of equation A-43 are implicitly a function of $P_{\infty}$ and $q_{c}$. Thus equation A-43 is actually nonlinear and the solutions for $P_{\infty}$ and $q_{c}$ must be extracted iteratively. Defining

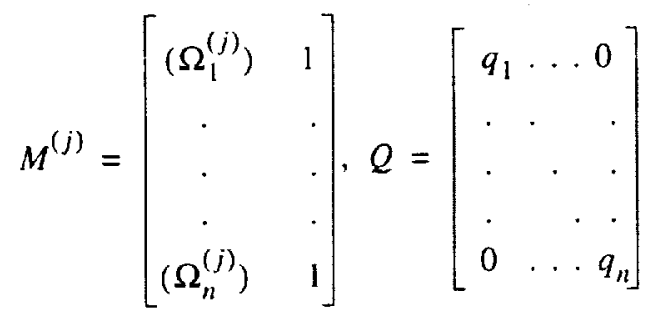

where $\Omega_{i}^{(j)}=\cos ^{2}\left(\theta_{i}\right)+\varepsilon^{(j)} \sin ^{2}\left(\theta_{i}\right)$, equation $A-43$ is written as an iterative estimator

$\left[\frac{\hat{q}_{c}}{\hat{P}_{\infty}}\right]_{(j+1)}=\left\{\left[M^{(j) T} Q M^{(j)}\right]^{-1} M^{(j) T} Q\right\}\left[\begin{array}{c}p_{1} \\ \cdot \\ \cdot \\ \cdot \\ p_{n}\end{array}\right](\mathrm{A}-45)$

In equation A-45 the subscript $(j)$ refers the result of the $j$ th iteration. The matrix $M^{(j)}$ is defined in equation A-44 with $\varepsilon$ being evaluated using the values for Mach number resulting from the previous iteration for $P_{\infty}$ and $q_{c}$.

\section{Algorithm Stability Analysis}

Since equation A-45 is to be implemented as part of a real-time airdata estimation algorithm, it is essential that potential instability regions be identified. In general it is impossible to analyze the stability of nonlinear equations with two unknowns; however, a linearized stability analysis will determine the behavior of the system with respect to small disturbances. Defining the terms

$$
\mathrm{Z} \equiv\left[\begin{array}{c}
p_{1} \\
\cdot \\
\cdot \\
p_{n}
\end{array}\right], \quad \mathrm{x} \equiv\left[\begin{array}{c}
q_{c} \\
P_{\infty}
\end{array}\right]
$$

and recalling that $\varepsilon$ is a function of Mach number, and implicitly a function of static and impact pressure, then

$$
M[x] \equiv\left[\begin{array}{cc}
\Omega_{1} & 1 \\
\cdot & \cdot \\
\cdot & \cdot \\
\Omega_{n} & 1
\end{array}\right]
$$

and equation A- 42 can be re-written as

$$
Z=M[x] x
$$

Using the definitions of equation A-46 and A-47, the iterative estimation equation can be written in the form

$$
Z=M\left[\hat{x}^{(j)}\right] \hat{x}^{(j+l)}
$$

In equation $A-49 \hat{x}^{(j+l)}$ is the estimate after the $j+l$ th iteration, and $M\left[\hat{x}^{(j)}\right]$ is the matrix of equation A-47 evaluated using the result from the $j$ th iteration. Subtracting equation A-49 from A-48, and expanding $M[x]$ in a Taylor series about $\hat{x}^{(j)}$ and neglecting terms higher than first order in the perturbations, equation A-49 reduces to

$$
\left[\nabla M_{x}^{(j)}\left(x-\hat{x}^{(j)}\right)\right] x+M\left[\hat{x}^{(j)}\right]\left(x-\hat{x}^{(j+I)}\right)=0
$$

Defining the error vectors,

$$
\begin{aligned}
\tilde{x}^{(j)} & \equiv\left(x-\hat{x}^{(j)}\right) \\
\bar{x}^{(j+l)} & \equiv\left(x-\hat{x}^{(j+l)}\right)
\end{aligned}
$$

Equation $\mathrm{A}-51$ becomes the linearized error equation for the iteration 


$$
\left[\nabla M_{x}^{(j)} x\right] \tilde{x}^{(j)}+M\left[\hat{x}^{(j)}\right] \tilde{x}^{(j+l)}=0
$$

and the eigenvalues (roots) of the characteristic equation $^{23}$

$\operatorname{Det}\left\{\left[\left(M\left[\hat{x}^{(j)}\right]^{T} M\left[\hat{x}^{(j)}\right]\right)^{-1}\left(M\left[\hat{x}^{(j)}\right]^{T}\left[\nabla M_{x}^{(j)} x\right]\right)\right]-\lambda \mathrm{I}\right\}=0$

will determine the linear stability of system. The elements of the Jacobian, $\nabla M_{x}^{(j)} x$, are evaluated as

$\nabla M_{x}^{(j)} x=$

$\left[\begin{array}{cc}q_{c} \sin ^{2} \theta_{1}\left(\frac{\partial \varepsilon^{(j)}}{\partial \mathrm{M}_{\infty}}\right)\left(\frac{\partial \mathrm{M}_{\infty}}{\partial q_{c}}\right) & q_{c} \sin ^{2} \theta_{1}\left(\frac{\partial \varepsilon^{(j)}}{\partial \mathrm{M}_{\infty}}\right)\left(\frac{\partial \mathrm{M}_{\infty}}{\partial P_{\infty}}\right) \\ \cdot \\ \cdot \\ \cdot \\ q_{c} \sin ^{2} \theta_{n}\left(\frac{\partial \varepsilon^{(j)}}{\partial \mathrm{M}_{\infty}}\right)\left(\frac{\partial \mathrm{M}_{\infty}}{\partial q_{c}}\right) & q_{c} \sin ^{2} \theta_{n}\left(\frac{\partial \varepsilon^{(j)}}{\partial \mathrm{M}_{\infty}}\right)\left(\frac{\partial \mathrm{M}_{\infty}}{\partial P_{\infty}}\right)\end{array}\right]$

In equation $\mathrm{A}-54$, the parameter $\frac{\partial \varepsilon}{\partial \mathrm{M}_{\infty}}$ is the sensitivity of the calibration parameter to Mach number and is determined by numerically differentiating the calibration parameter $\left(\varepsilon_{M}\right)$ with respect to Mach number. The parameters $\frac{\partial \mathrm{M}_{\infty}}{\partial q_{c}}$, and $\frac{\partial \mathrm{M}_{\infty}}{\partial P_{\infty}}$ are evaluated by differentiating the isentropic flow equation (eq. 9(a)) for subsonic flow, or the Rayleigh pitot equation (eq. 9 (b)) for supersonic flow. For $\gamma=1.4$, the resulting expressions are

$$
\begin{gathered}
\frac{\partial \mathbf{M}_{\infty}}{\partial q_{c}}=\frac{1}{P_{\infty}\left(\frac{\partial f}{\partial M}\right)} \\
\frac{\partial M}{\partial P_{\infty}}=\frac{-q_{c}}{P_{\infty}^{2}\left(\frac{\partial f}{\partial M}\right)}
\end{gathered}
$$

where the Mach number derivative is

$$
\begin{aligned}
\left(\frac{\partial f}{\partial M}\right)_{\text {subsonic }}= & 1.4 \mathrm{M}_{\infty}\left[1+0.2 \mathrm{M}_{\infty}^{2}\right]^{2.5} \\
& \operatorname{for}\left(M_{\infty} \leq 1\right) \\
\left(\frac{\partial f}{\partial M}\right)_{\text {supersonic }} & 1168.45 \mathrm{M}_{\infty}^{6} \frac{\left[2 \mathrm{M}_{\infty}^{2}-1\right]}{\left.\left[7 \mathrm{M}_{\infty}^{2}-1\right]\right]^{3.5}} \\
& \text { for }\left(M_{\infty}>1\right)
\end{aligned}
$$

Substituting equation A-55 into A-54, the Jacobian matrix reduces to

$$
\begin{gathered}
\nabla M_{x}^{(j)} x= \\
{\left[\frac{q_{c}}{P_{\infty}}\right] \sin ^{2} \theta_{1}\left[\frac{\partial \varepsilon^{(j)}}{\partial \mathrm{M}_{\infty}}\right] \frac{\frac{1}{\partial f}}{\partial M}-\left[\frac{q_{c}}{P_{\infty}}\right]^{2} \sin ^{2} \theta_{1}\left[\frac{\partial \varepsilon^{(j)}}{\partial \mathrm{M}_{\infty}}\right] \frac{1}{\partial f}} \\
\cdot \\
\left.\left[\frac{q_{c}}{P_{\infty}}\right] \sin ^{2} \theta_{n}\left[\frac{\partial \varepsilon^{(j)}}{\partial \mathrm{M}_{\infty}}\right] \frac{\frac{1}{\partial f}}{\partial M}-\left[\frac{q_{c}}{P_{\infty}}\right]^{2} \sin ^{2} \theta_{n}\left[\frac{\partial \varepsilon^{(j)}}{\partial \mathrm{M}_{\infty}}\right] \frac{\frac{1}{\partial f}}{\partial M}\right]
\end{gathered}
$$

Equation A-57 is dependent only on the free stream Mach number and the local incidence angles; thus for a given port geometry, the stability of the system (eigenvalues equation A-53) is dependent only on the free stream Mach number and the local flow incidence angles. This conclusion is very important, as it allows the stability characteristics of the system to be analyzed independently of trajectory.

\section{$\underline{\text { References }}$}

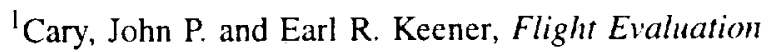
of the X-15 Ball-Nose Flow-Direction Sensor as an AirData System, NASA TN D-2923.

${ }^{2}$ Siemers, Paul M., III, Martin W. Henry, and James B. Eades, Jr., "Shuttle Entry Air Data System (SEADS)Advanced Air Data System Results: Air Data Across the Entry Speed Range," Orbiter Experiments (OEX) Aerothermodynamics Symposium, CP 3248, Part I, Apr. 1995, pp. 49-78.

${ }^{3}$ While, D.M., Shuttle Entry Air Data System (SEADS) Hardware Development, Vol. II, History; NASA CR-166044, Jan. 1983. 
${ }^{4}$ Larson, Terry J., Stephen A. Whitmore, L. J. Ehernberger, J. Blair Johnson, and Paul M. Siemers, III, Qualitative Evaluation of a Flush Air Data System at Transonic Speeds and High Angles of Attack, NASA TP-2716, Apr. 1987.

${ }^{5}$ Larson, Terry J., Timothy R. Moes, and Paul M. Siemers, III, Wind-Tunnel Investigation of a Flush Airdata System at Mach Numbers From 0.7 to 1.4, NASA TM-101697, Apr. 1990.

${ }^{6}$ Whitmore, Stephen A., Timothy R. Moes, and Terry J. Larson, Preliminary Results From a Subsonic High Angle-of-Attack Flush Airdata Sensing (HI-FADS) System: Design, Calibration, and Flight Test Evaluation, NASA TM-101713, Jan. 1990.

${ }^{7}$ Whitmore, Stephen A., Roy J. Davis, and John Michael Fife, In-Flight Demonstration of a Real-Time Flush Airdata Sensing System, AIAA Journal of Aircraft, vol. 33, no. 5, Sept.-Oct., 1996, pp. 970-977.

${ }^{8}$ Currie, I. G., Fundamental Mechanics of Fluid, McGraw-Hill Book Company, New York, 1974.

${ }^{9}$ Anderson, John D., Jr., Hypersonic and High Temperature Gas Dynamics, McGraw-Hill Book Company, New York, 1989.

${ }^{10}$ Boyer, Howard E. and Timothy L. Gall, Metals Handbook ${ }^{\circledR}$, Desk Edition, American Society for Metals, Metals Park, Ohio, pp. 16-23, 16-25.

${ }^{11}$ Diefendorf, Russell J., "Continuous Carbon Fiber Reinforced Carbon Matrix Composites," Engineered Materials Handbook ${ }^{\mathrm{TM}}$, Volume 1: Composites, AMS International, Metals Park, Ohio, 1989, pp. 91 1-924.

${ }^{12}$ Whitmore, Stephen A., Development of a Pneumatic High-Angle-of-Attack Flush Airdata Sensing System, SAE-912142, Sept. 1991.

${ }^{13}$ Whitmore, Stephen A., and Timothy R. Moes, Failure Detection and Fault Management Techniques for a Pneumatic High-Angle-of-Attack Flush Airdata Sensing (HI-FADS) System, NASA TM-4335, Jan. 1992.
${ }^{14}$ Whitmore, Stephen A., Roy J. Davis, and John Michael Fife, In-Flight Demonstration of a Real-Time Flush Airdata Sensing (RT-FADS) System, AIAA-95-3433, Aug. 1995.

${ }^{15}$ Shapiro, Ascher H., The Dynamics and Thermodynamics of Compressible Fluid Flow, Volume I, John Wiley Sons, New York, 1953, pp. 83-88, 154.

${ }^{16}$ Haering, E. A., Jr., Airdata Calibration Techniques for Measuring Atmospheric Wind Profiles, Journal of Aircraft, Vol. 29, No. 4, Jul.-Aug., 1992, pp. 632-639.

${ }^{17}$ Whitmore, Stephen A. and Timothy R. Moes, Measurement Uncertainty and Feasibility Study of a Flush Airdata System for a Hypersonic Flight Experiment, AIAA-94-1930, June 1994.

${ }^{18}$ Huber, Paul W., Hypersonic Shock-Heated Flow Parameters for Velocities to 46,000 Feet Per Second and Altitudes to 323,000 Feet, NASA TR R-163, Langley Research Center, Hampton Virginia, Dec. 1963.

${ }^{19}$ Franklin, Gene F., and J. David Powell, Digital Control of Dynamic Systems, Addison-Wesley Publishing Company, Reading, Massachusetts, 1980.

${ }^{20}$ Capone, Francis J., Linda S. Bangert, Scott C. Asbury, Charles T. L. Mills, and E. Ann Bare, The NASA Langley 16-Foot Transonic Tunnel: Historical Overview; Facility Description, Calibration, Flow Characteristics, and Test Capabilities, NASA TP-3521, Sept. 1995.

${ }^{21}$ Jackson, Charlie M., Jr., William A. Corlett, and William J. Monta, Description and Calibration of the Langley Unitary Plan Wind Tunnel, NASA TP-1905, Nov. 1981.

${ }^{22}$ Bendat, Julius S. and Allan G. Piersol, Random Data: Analysis and Measurement Procedures, WileyInterscience, a division of John Wiley \& Sons, Inc., New York, 1971.

${ }^{23}$ Freiberger, W.F., ed., The International Dictionary of Applied Mathematics, D. Van Nostrand Company, Inc., Princeton, New Jersey, 1960. 


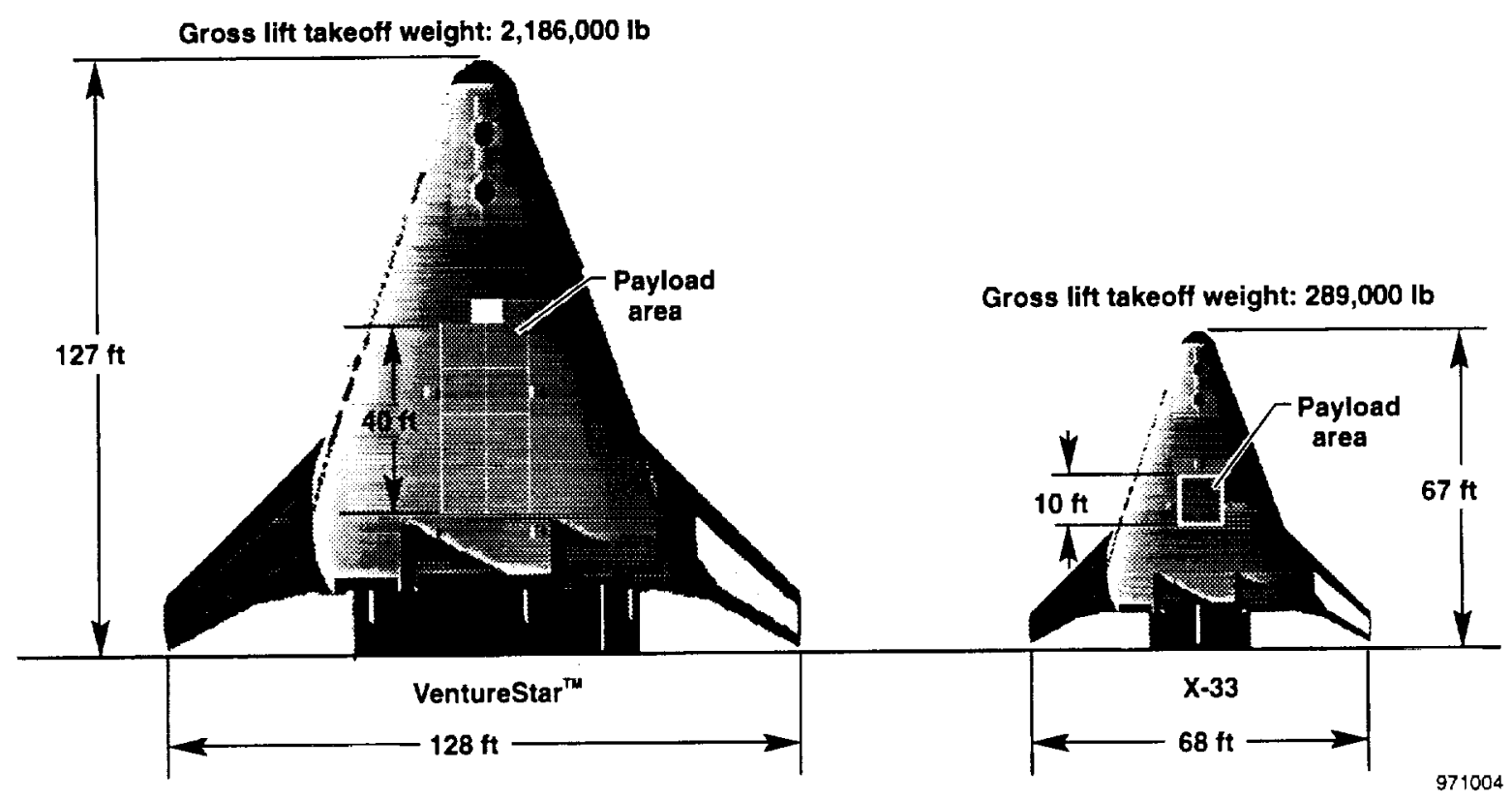

Figure 1. A comparison of the VentureStar ${ }^{\mathrm{TM}}$ and X-33 vehicles.

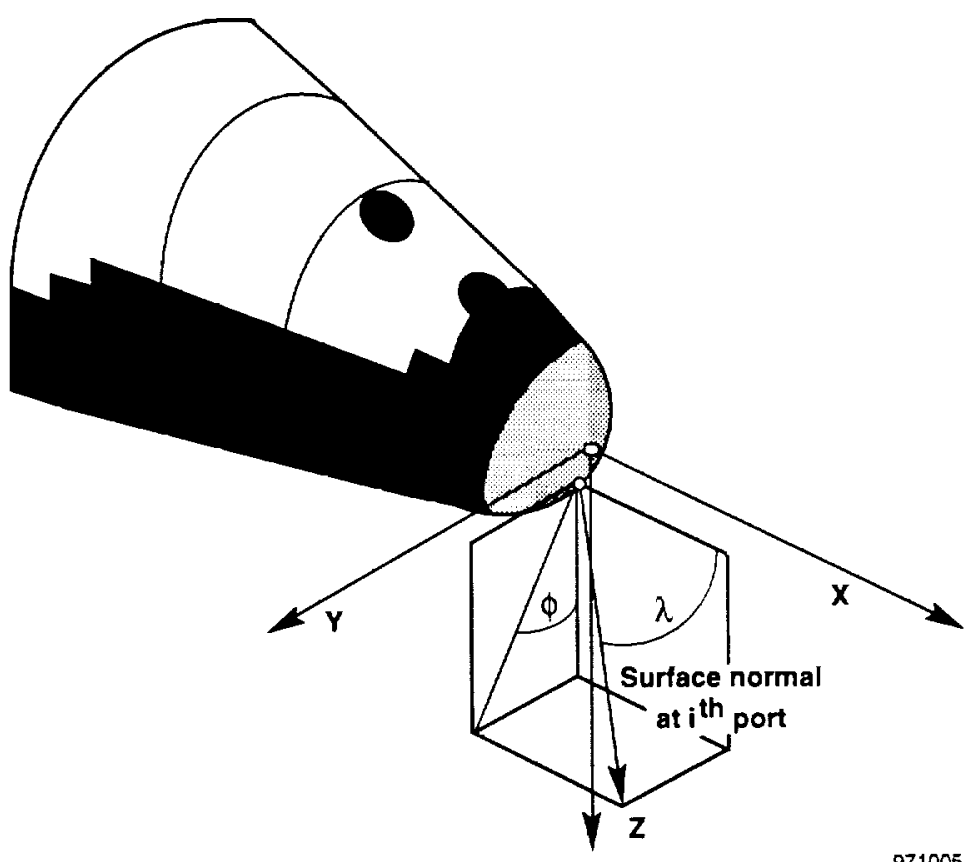

Figure 2. Clock and cone angle definitions. 


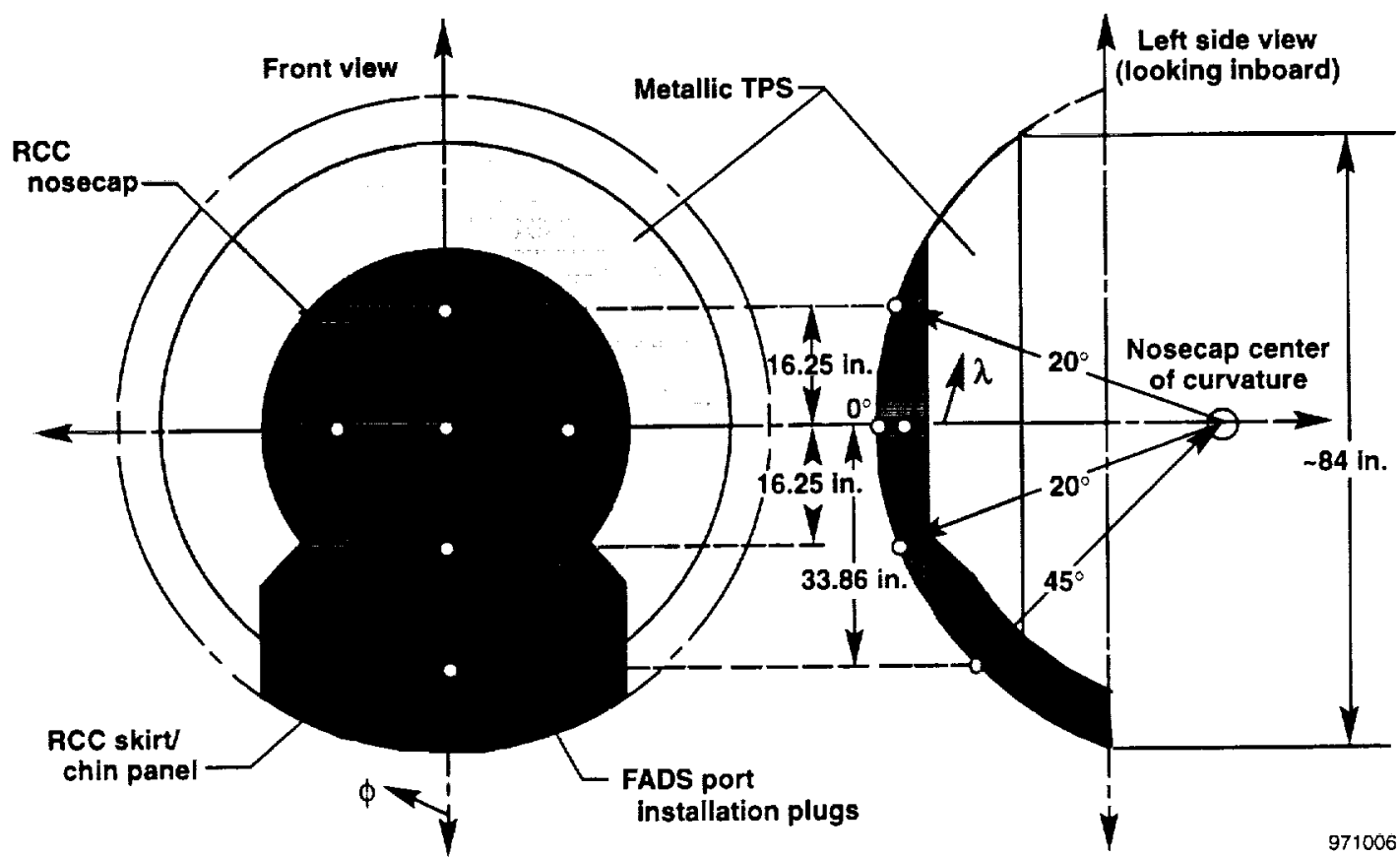

Figure 3. X-33 surface measurement locations.

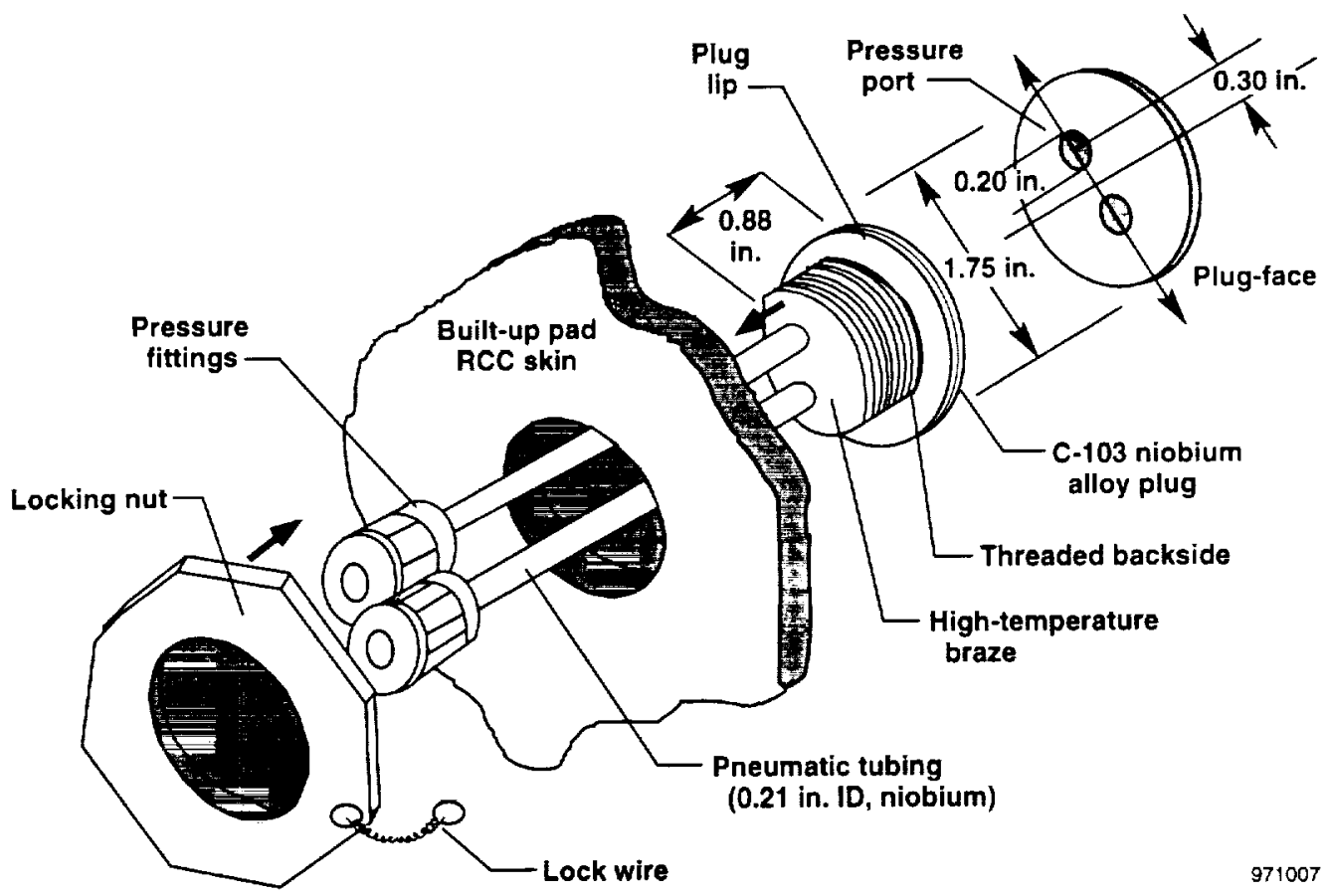

Figure 4. Exploded view of X-33 FADS pressure plug design. 


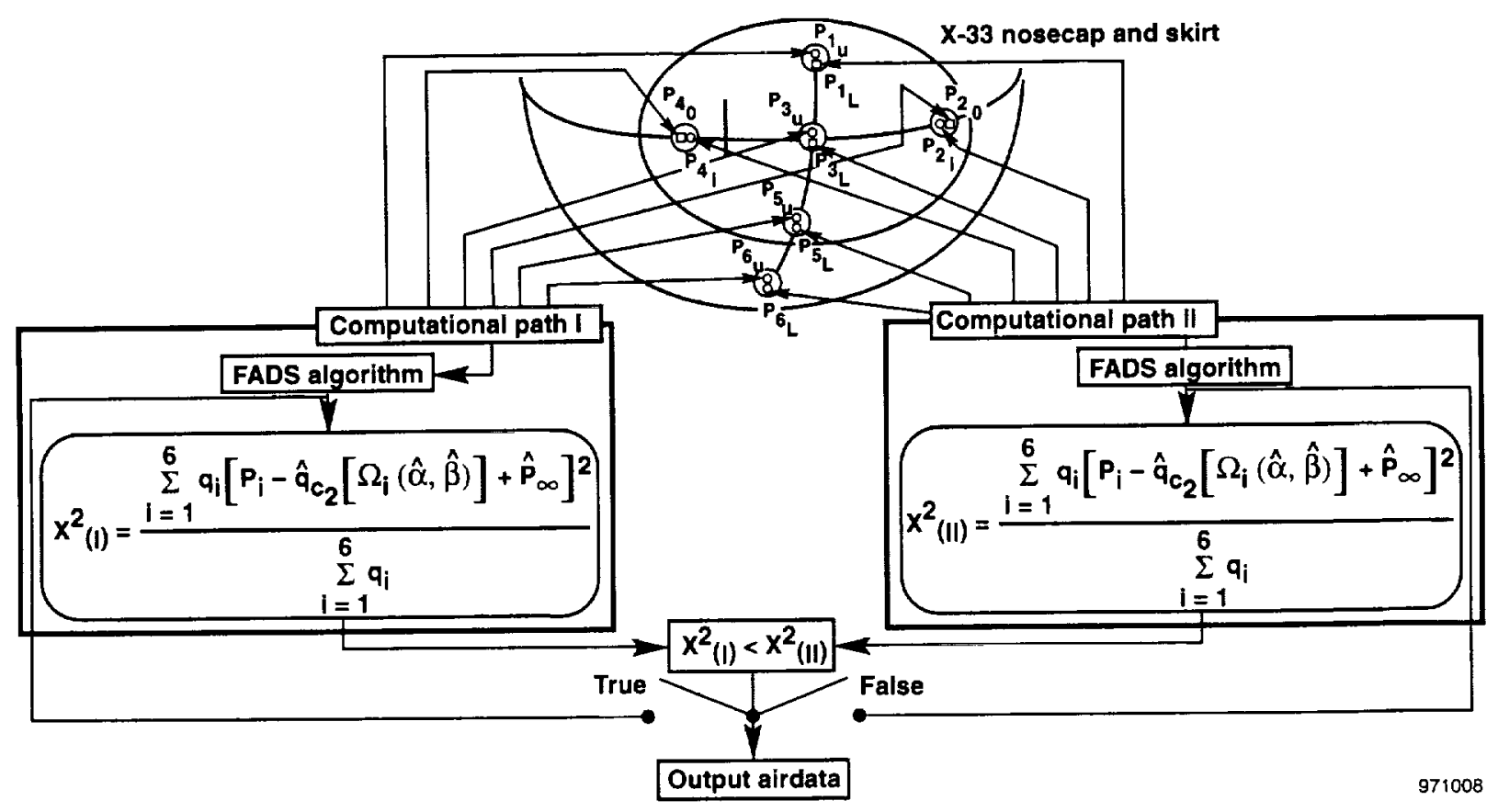

Figure 5. X-33 FADS computational architecture.

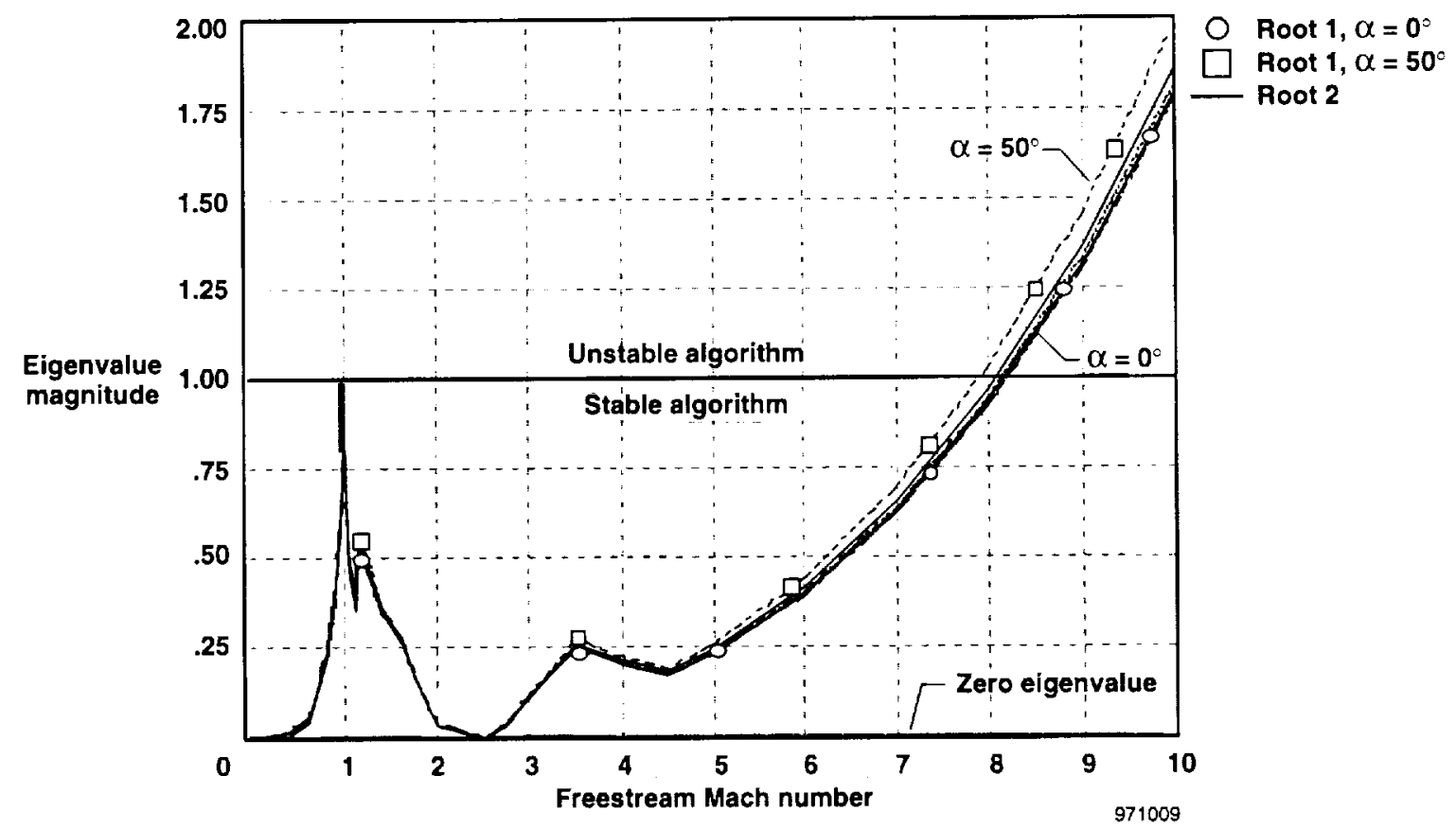

Figure 6. Stability of the FADS Mach number iteration. 


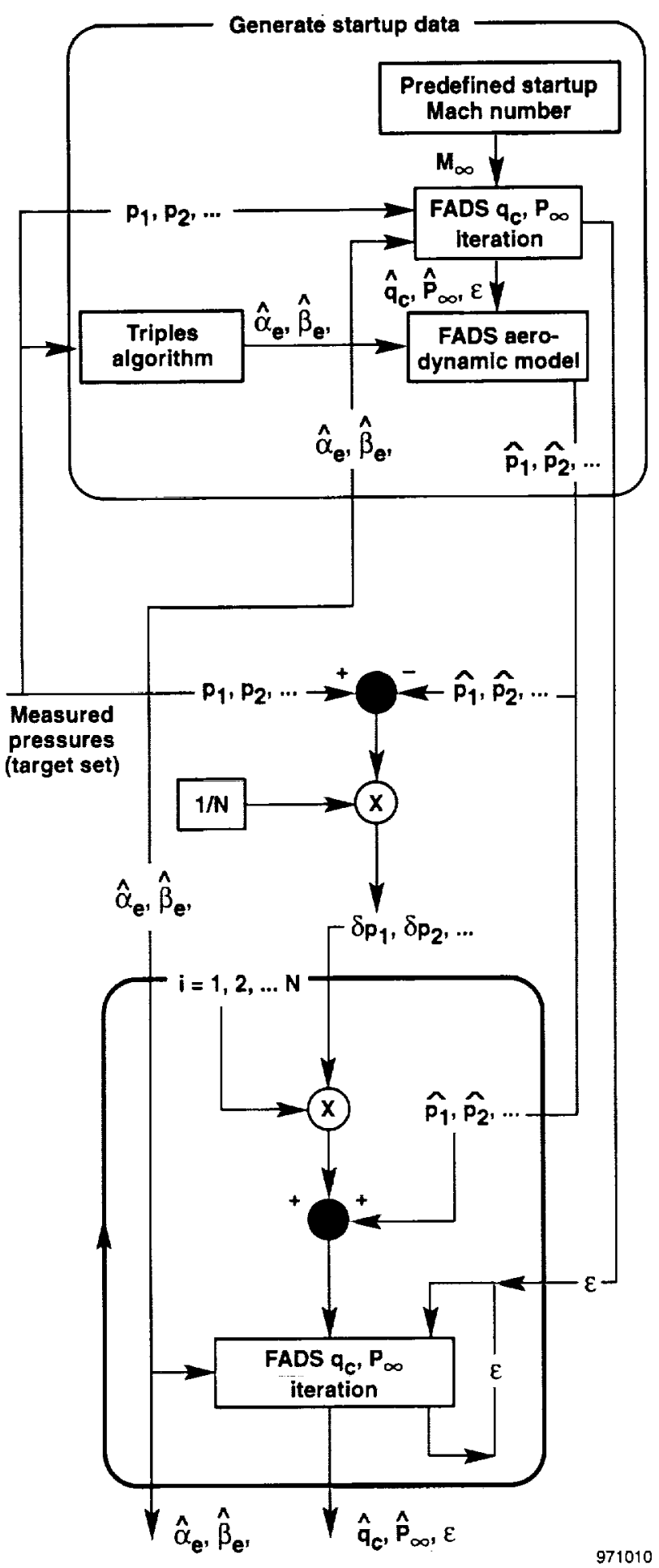

Figure 7. The FADS startup algorithm. 


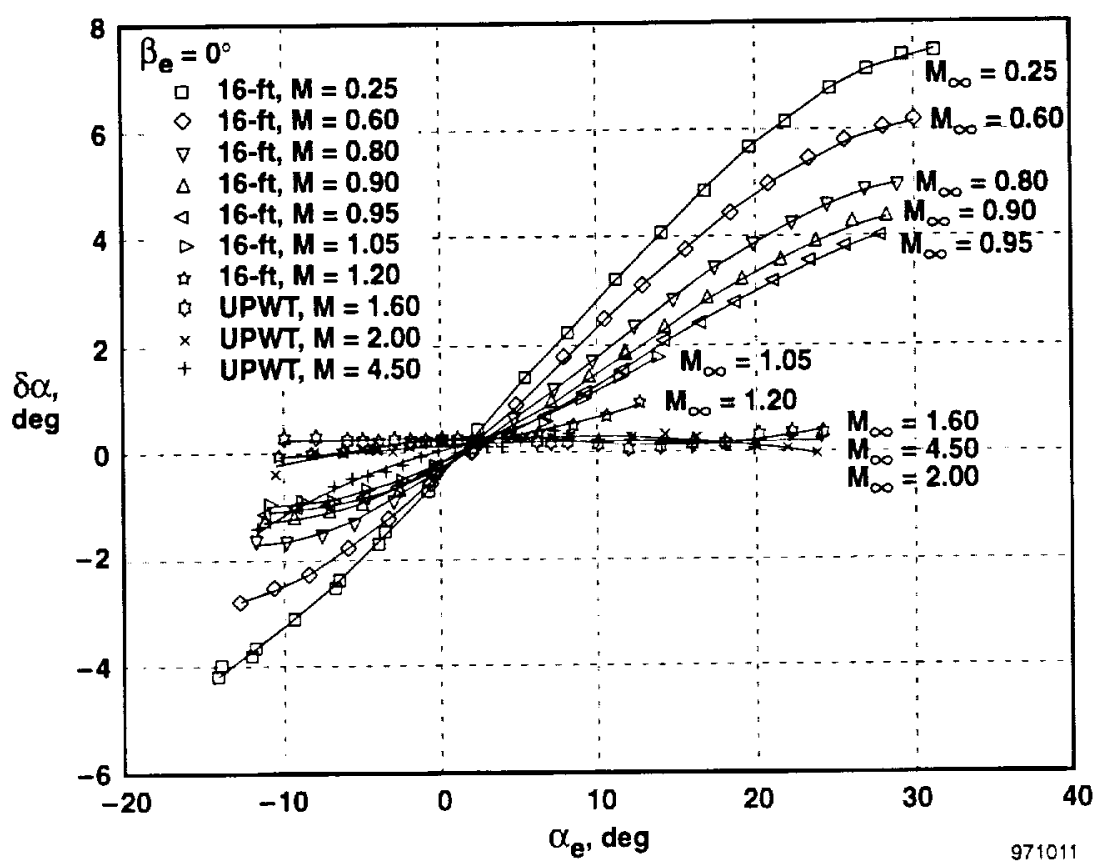

Figure 8. FADS angle-of-attack wind tunnel calibration.

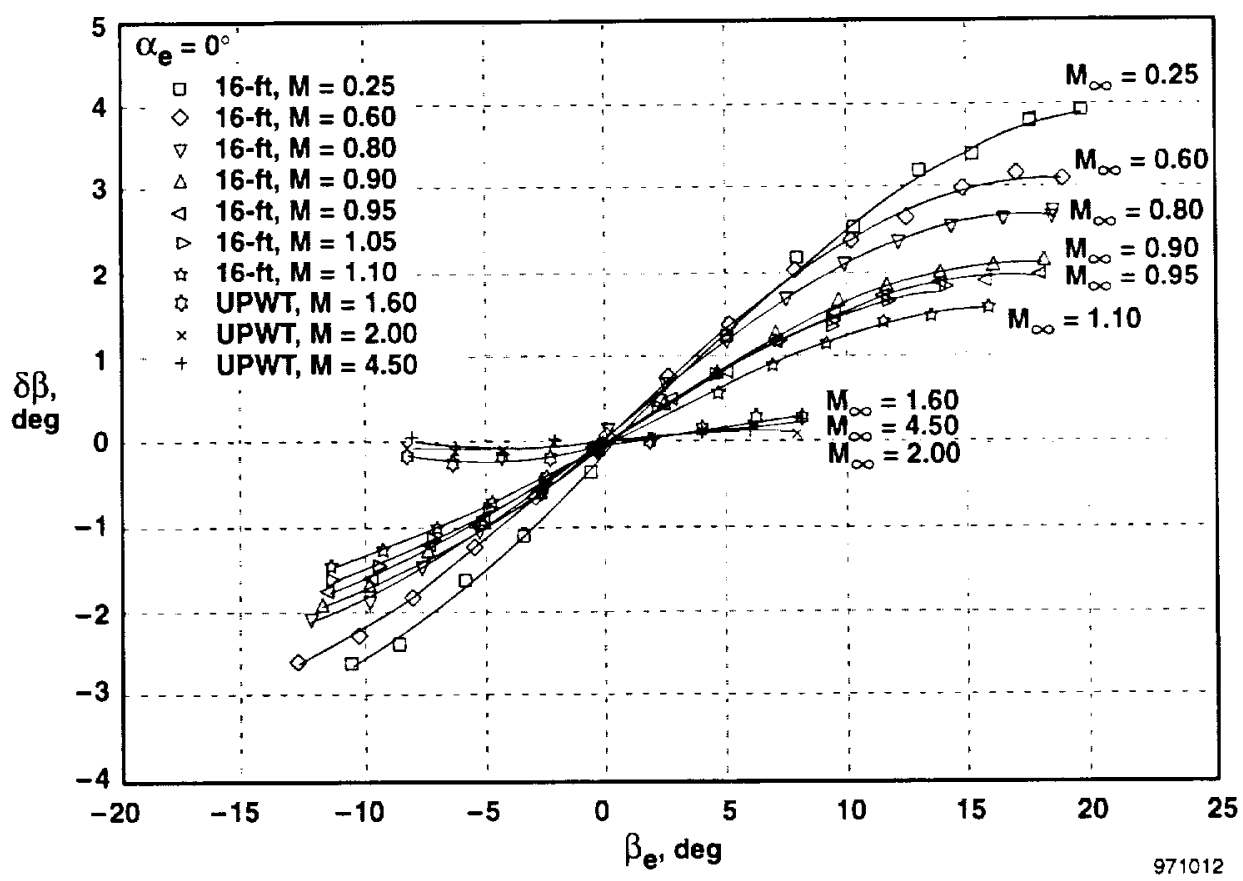

Figure 9. FADS angle-of-sideslip wind tunnel calibration. 


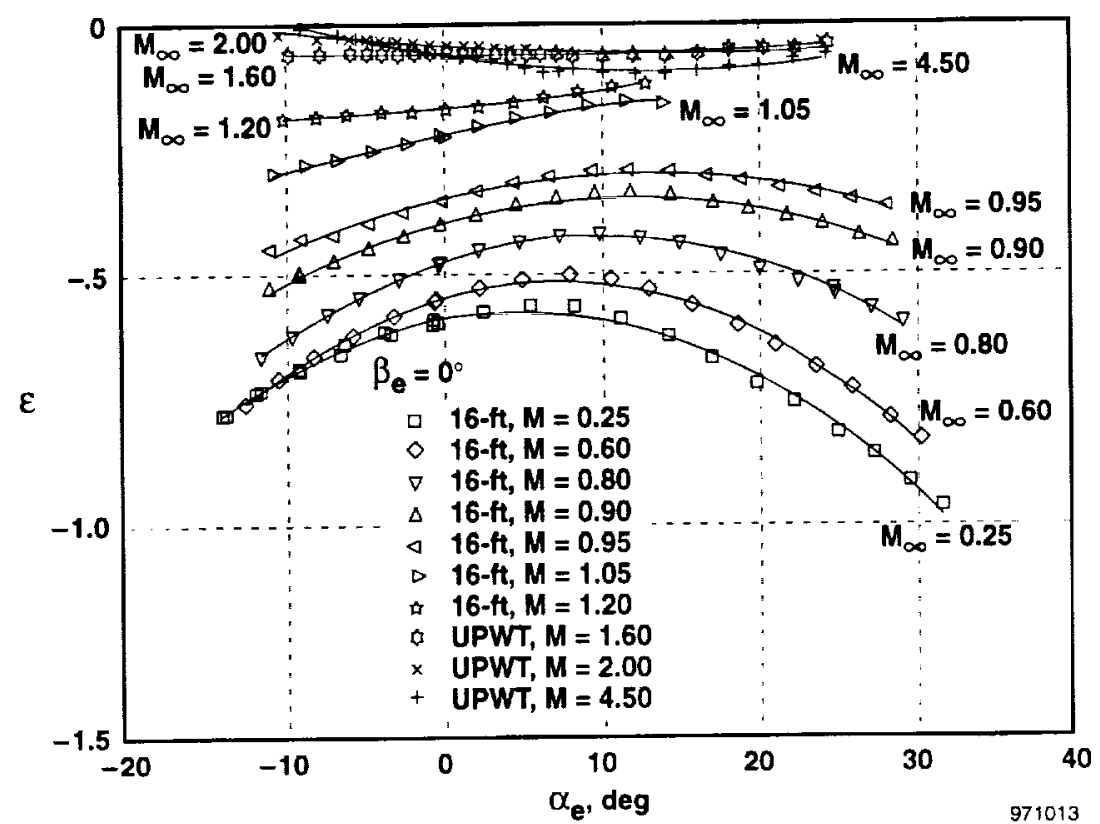

(a) Variation with angle of attack.

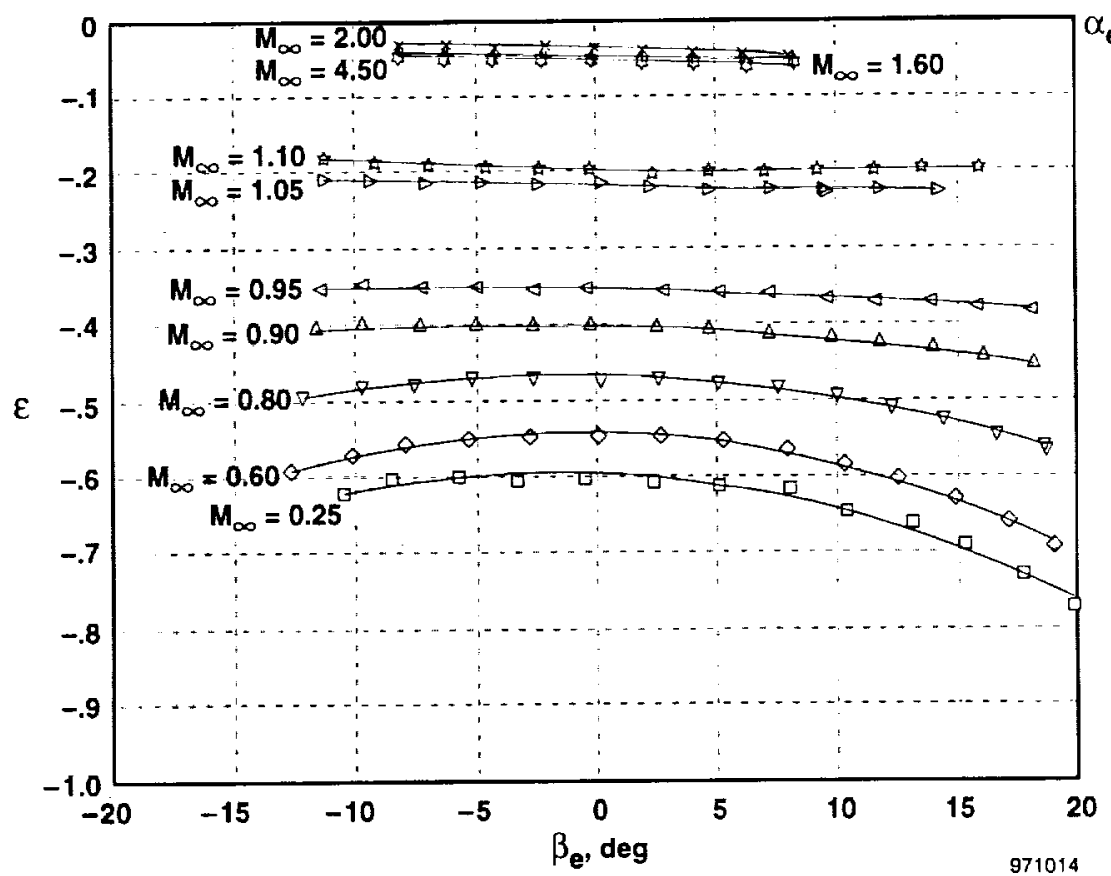

$$
\begin{aligned}
& \alpha_{e}=0^{\circ} \\
& \text { 16-ft, } M=0.25 \\
& \text { 16-ft, } M=0.60 \\
& \nabla \quad \text { 16-ft, } M=0.80 \\
& \therefore \quad \text { 16-ft, } M=0.90 \\
& \text { ( 16-ft, } M=0.95 \\
& \text { b 16-ft, } M=1.05 \\
& 16-\mathrm{ft}, M=1.10 \\
& \text { UPWT, M }=1.60 \\
& \text { UPWT, } M=2.00 \\
& \text { UPWT, } M=4.50
\end{aligned}
$$

(b) Variation with angle of sideslip.

Figure 10. FADS position error coefficient wind tunnel calibration. 


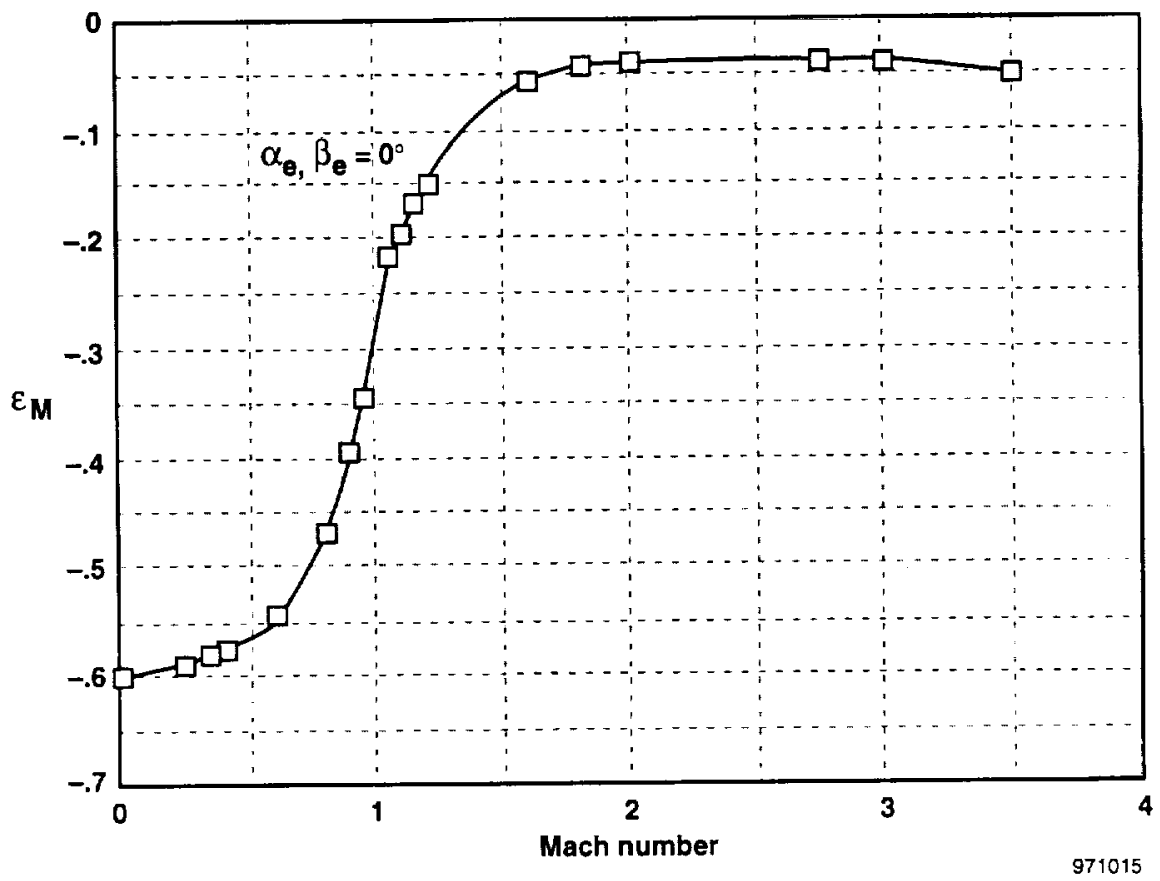

(c) Variation with Mach number.

Figure 10. Concluded.

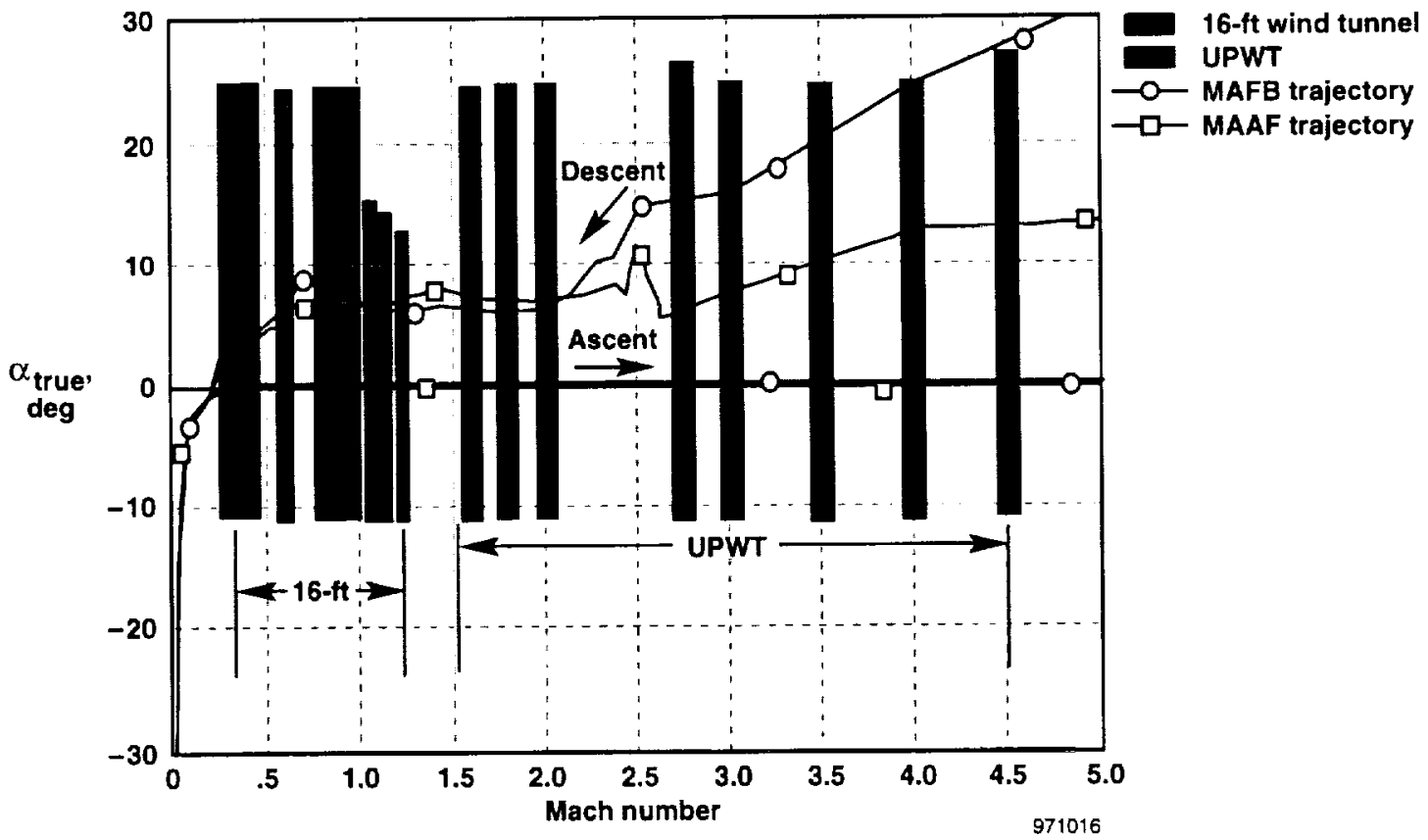

Figure 11. A comparison of the FADS wind tunnel points and X-33 trajectories. 


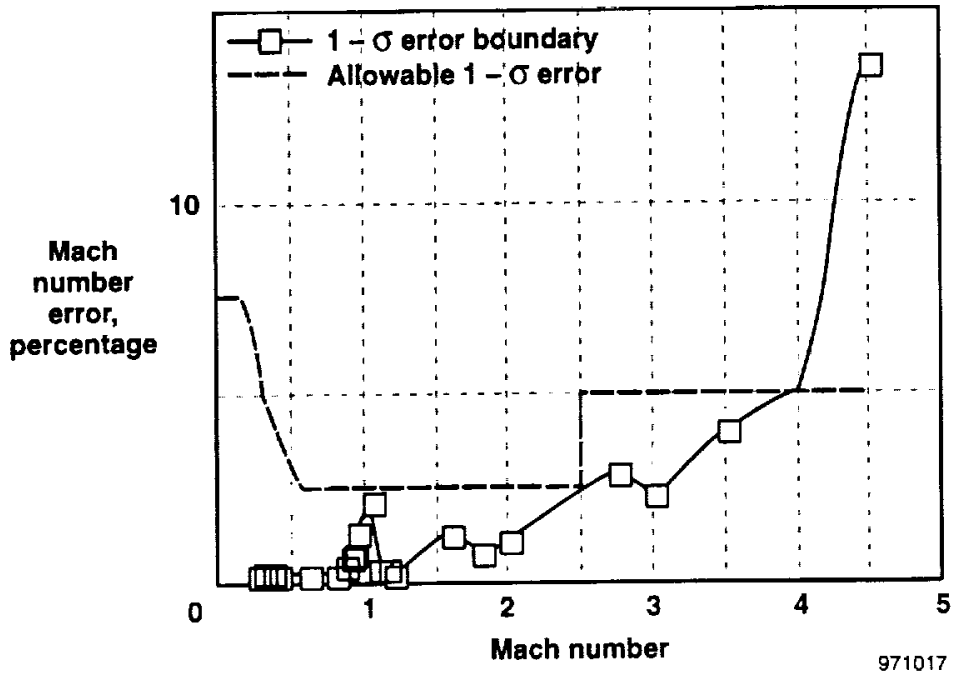

(a) Percentage Mach number error.

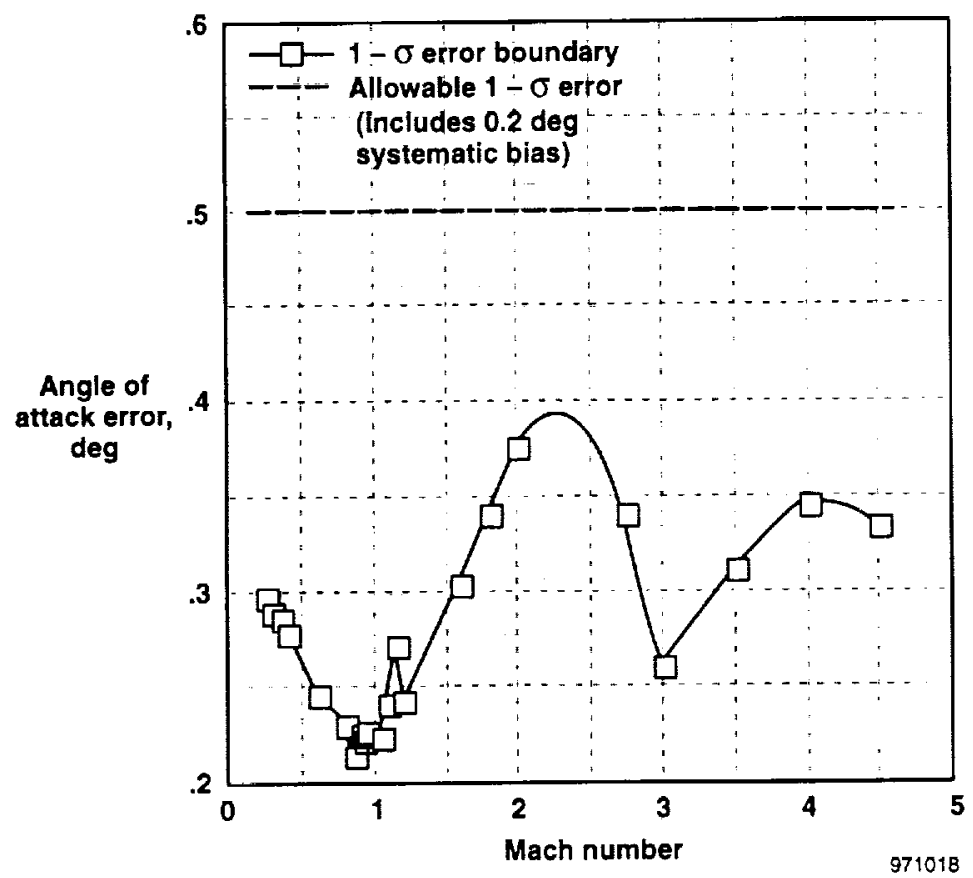

(b) Angle of attack error.

Figure 12. X-33 FADS error estimates. 


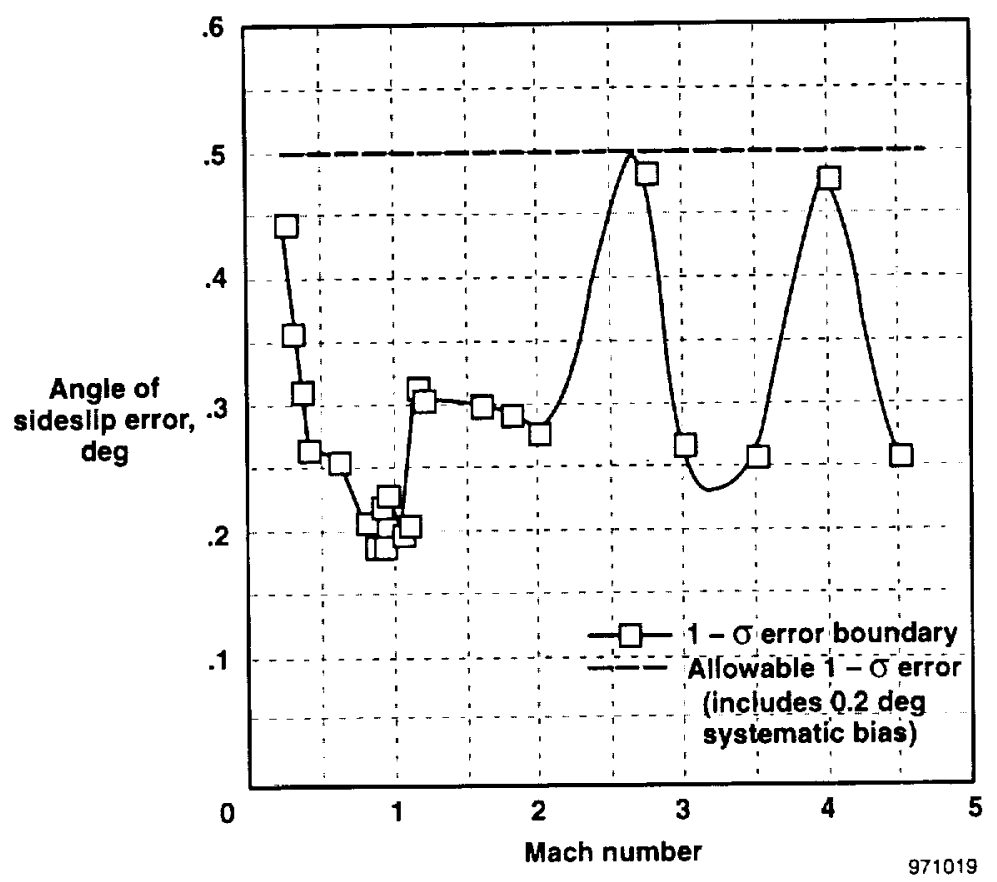

(c) Angle of sideslip error.

Figure 12. Concluded.

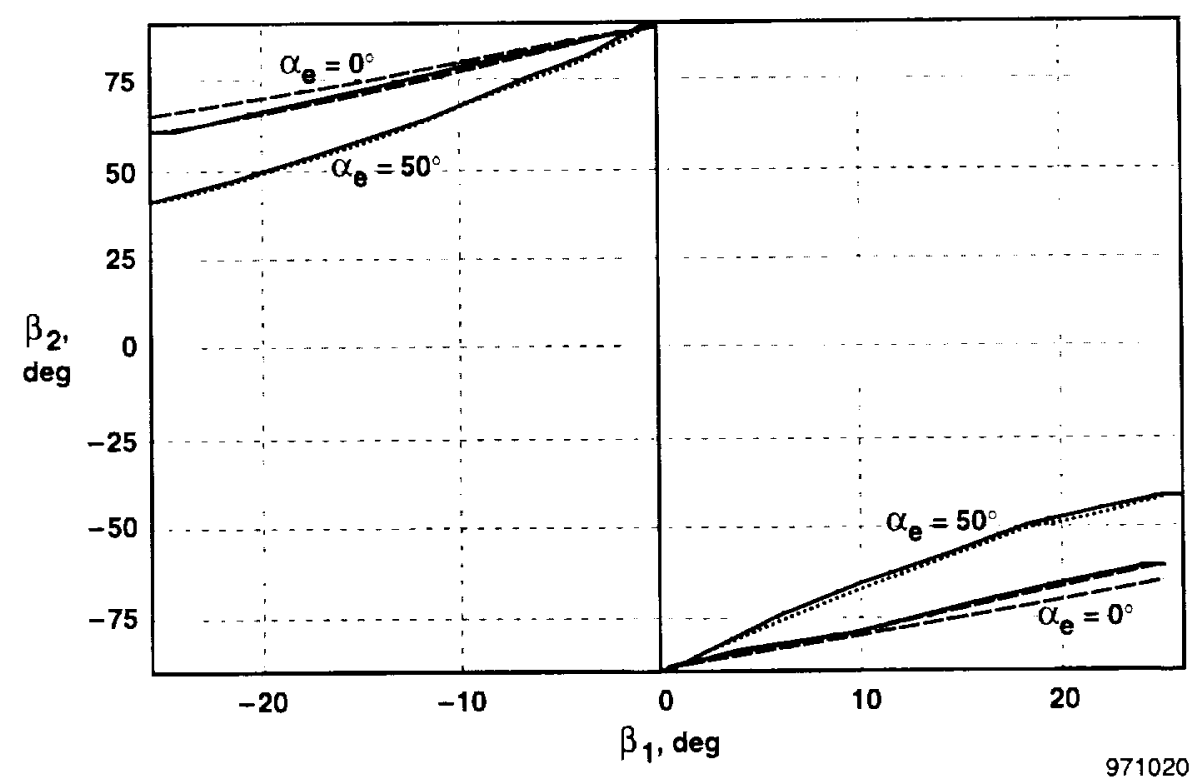

Figure A-1. Lateral meridian triples: A comparison of $\beta$ solutions. 


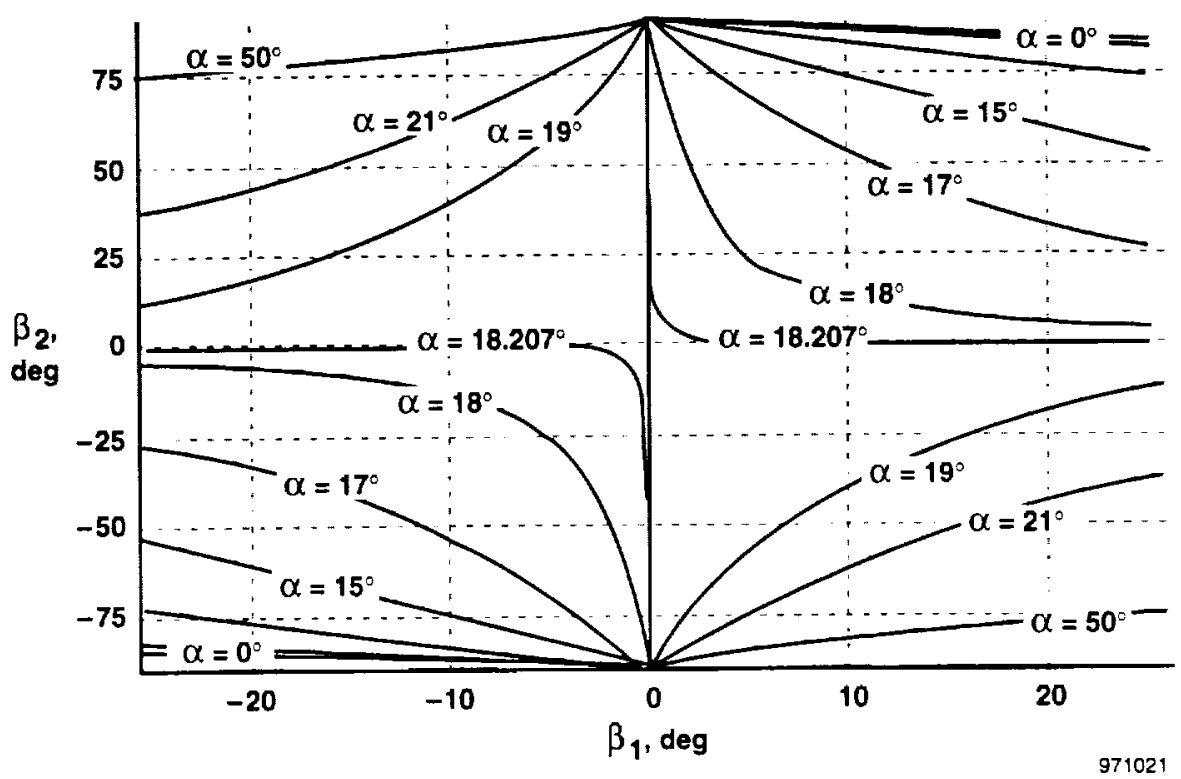

(a) Ports 2, 4, and 6.

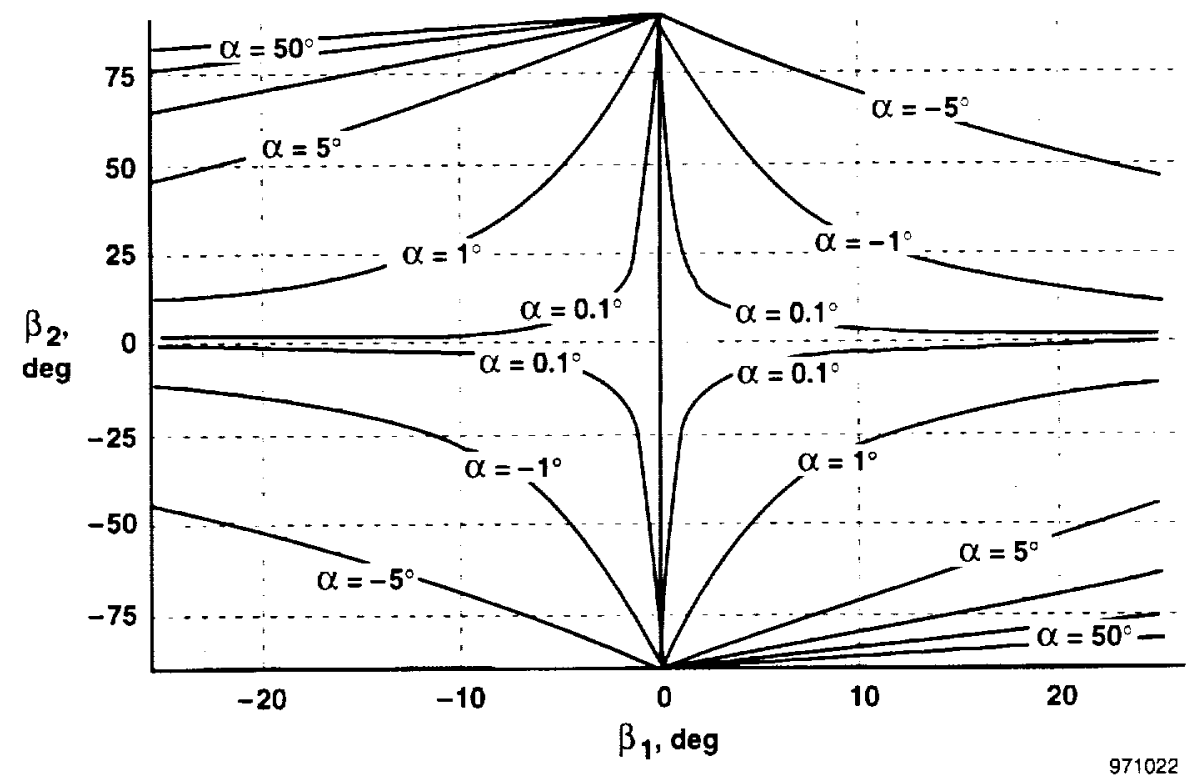

(b) Ports 2, 4, and 5.

Figure A-2. Comparison of $\beta$ solutions, off-meridian triples, symmetric arrangement. 


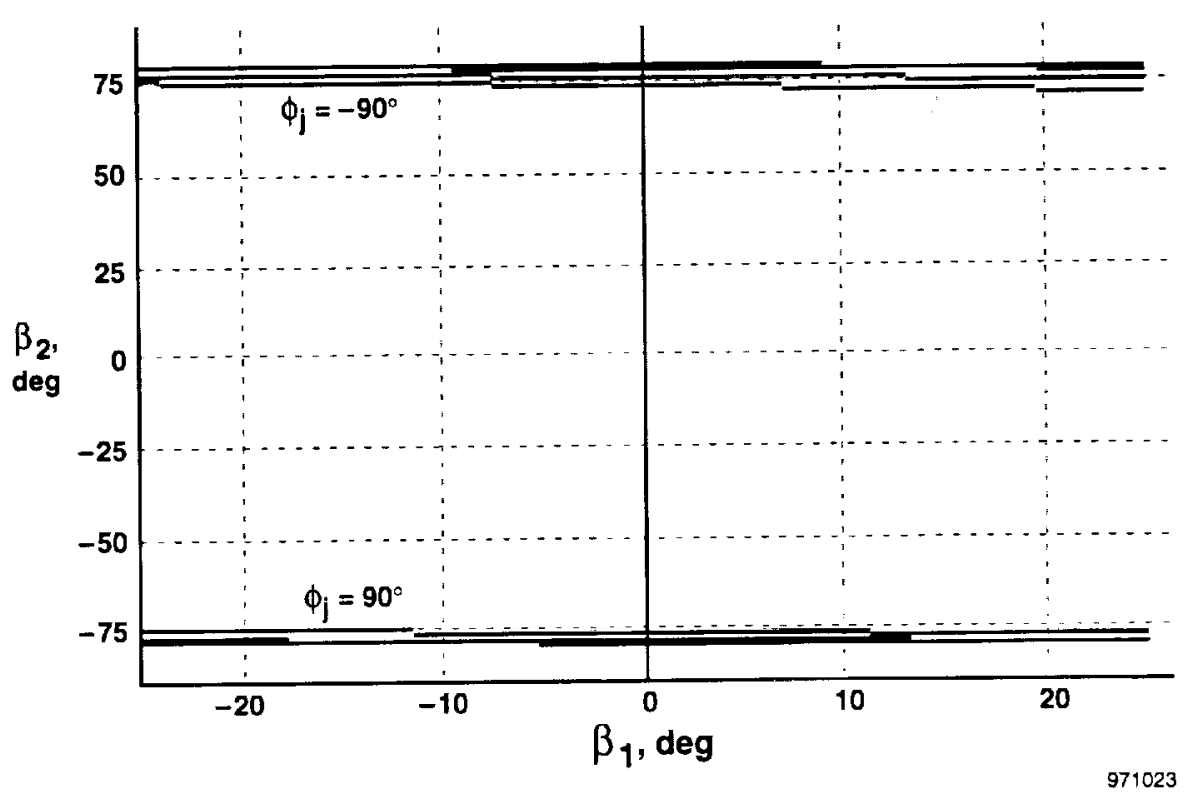

(a) Ports 2 or 4, 3, and 6 .

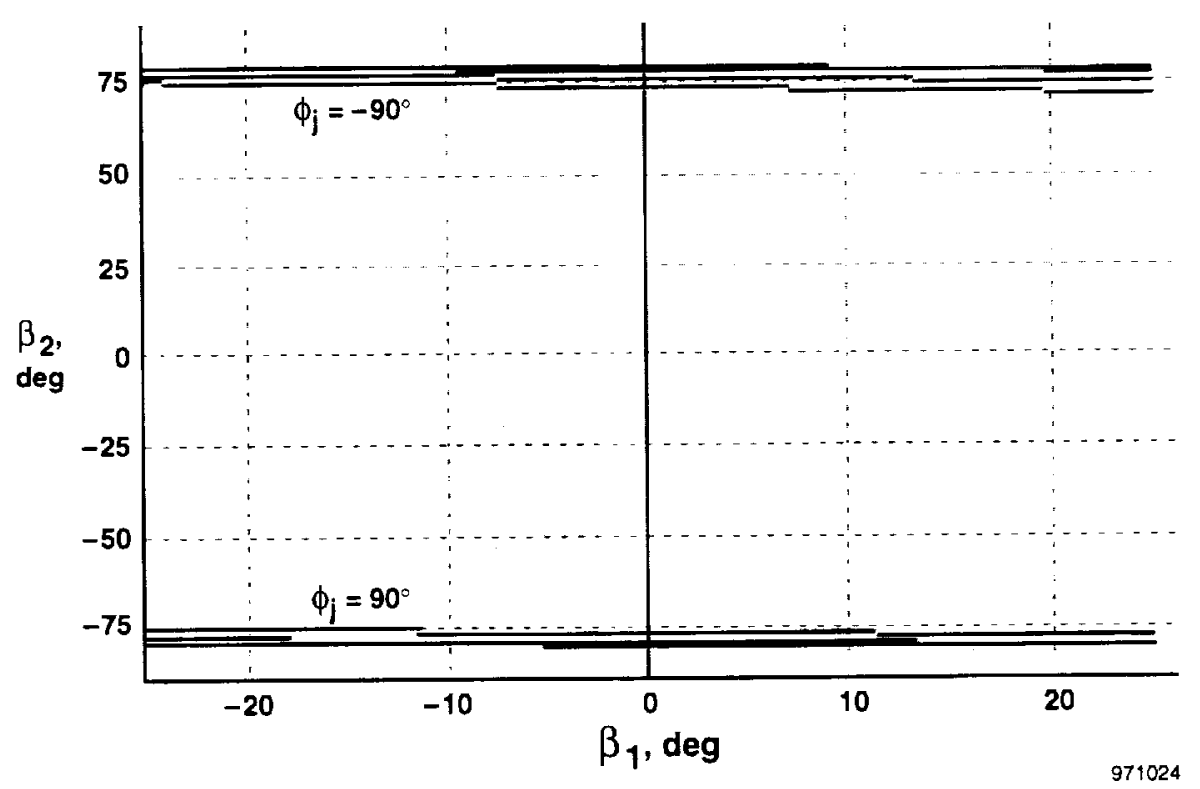

(b) Ports 2 or 4, 3, and 5.

Figure A-3. Comparison of $\beta$ solutions, off-meridian triples, asymmetric arrangement. 
Public reporting burden for this collection of information is estimated to average 1 hour per response, including the time for reviewing instructlons, searching existing data sources, gathering and maintaining the data needed, and completing and reviewing the collection of intormation. Send comments regarding this burden estimate or any other aspect of this collection of information,

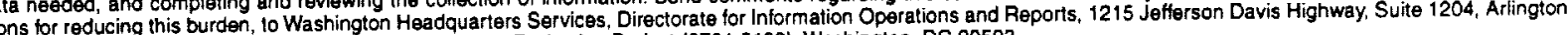
VA 22202-4302, and to the Office of Management and Budget, Paperwork Reduction Project (0704-0188), Washington, DC 20503.

\begin{tabular}{|l|l|l|}
\hline 1. AGENCY USE ONLY (Leave blank) & $\begin{array}{l}\text { 2. REPORT DATE } \\
\text { January } 1998\end{array}$ & $\begin{array}{l}\text { 3. REPORT TYPE AND DATES COVERED } \\
\text { Technical Memorandum }\end{array}$ \\
\hline
\end{tabular}

4. TITLE AND SUBTITLE

Design and Calibration of the X-33 Flush Airdata Sensing (FADS) System

6. AUTHOR(S)

Stephen A. Whitmore, Brent R. Cobleigh, and Edward A. Haering

242-33-02-00-23-00-TA3

7. PERFORMING ORGANIZATION NAME(S) AND ADDRESS(ES)

NASA Dryden Flight Research Center

P.O. Box 273

Edwards, California 93523-0273

9. SPONSORING/MONITORING AGENCY NAME(S) AND ADDRESS(ES)

National Aeronautics and Space Administration

Washington, DC 20546-0001

B. PERFORMING ORGANIZATION REPORT NUMBER

H-2219

10. SPONSORINGMONITORING AGENCY REPORT NUMBER

NASA/TM-1998-206540

11. SUPPLEMENTARY NOTES

Presented at the AIAA Aerospace Sciences Meeting and Exhibit, January 12-15, 1998, Reno, Nevada. AIAA-98-0201

12a. DISTRIBUTION/AVAILABILTY STATEMENT

12b. DISTRIBUTION CODE

Unclassified-Unlimited

Subject Category 06

13. ABSTRACT (Maximum 200 words)

This paper presents the design of the X-33 Flush Airdata Sensing (FADS) system. The X-33 FADS uses a matrix of pressure orifices on the vehicle nose to estimate airdata parameters. The system is designed with dual-redundant measurement hardware, which produces two independent measurement paths. Airdata parameters that correspond to the measurement path with the minimum fit error are selected as the output values. This method enables a single sensor failure to occur with minimal degrading of the system performance. The paper shows the X-33 FADS architecture, derives the estimating algorithms, and demonstrates a mathematical analysis of the FADS system stability. Preliminary aerodynamic calibrations are also presented here. The calibration parameters, the position error coefficient $(\mathcal{E})$, and flow correction terms for the angle of attack $(\delta \alpha)$, and angle of sideslip $(\delta \beta)$ are derived from wind tunnel data. Statistical accuracy of the calibration is evaluated by comparing the wind tunnel reference conditions to the airdata parameters estimated. This comparison is accomplished by applying the calibrated FADS algorithm to the sensed wind tunnel pressures. When the resulting accuracy estimates are compared to accuracy requirements for the X-33 airdata, the FADS system meets these requirements.

\section{SUBJECT TERMS}

FADS Calibration, Flush airdata sensing (FADS), X-33, Redundancy Management, Reusable Launch Vehicle (RLV)

\begin{tabular}{|l|l|l|}
\hline 17. SECURTY CLASSIFICATION & $\begin{array}{l}\text { 18. SECURTY CLASSIFICATION } \\
\text { OF THIS PAGE } \\
\text { OF REPORT } \\
\text { Unclassified }\end{array}$ & $\begin{array}{l}\text { 19. SECURITY CLASSIFICATION } \\
\text { OF ABSTRACT } \\
\text { Unclassified }\end{array}$ \\
\hline
\end{tabular}

15. NUMBER OF PAGES 36 16. PRICE CODE $\mathrm{A} 03$ 20. LIMITATION OF ABSTRACT

Unlimited 